\title{
Cuerpos Públicos, Cartas Privadas (ss. XVI-XVII)
}

\author{
Coral Cuadrada* and Enric Olartecoechea* \\ Universitat Rovira i Virgili, Tarragona, Spain \\ Colectivo La Fondona, Barcelona, Spain
}

\begin{abstract}
The analysis of the correspondence between two sixteenth/seventeenthcentury female aristocrats -Luisa de Carvajal, Magdalena de San Jerónimo- enables us to reflect on the value of relics and their relevance in the Spanish Baroque Counter-Reformation. We correlate Luisa's yearning for martyrdom as well as her mystical and religious exaltation with some of Magdalena's commitments -at the Penitents House, at the Flemish Court, and as founder of the prison for prostitutes and female delinquents known as the Casa de la Galera-, and, therefore, with different bodies and semiotics: the ill body of men, that polluting of 'working girls'; the bodies of virgins, of prostitutes, of actresses. These relate to different public spaces: the brothel, the theatre, the Magdalene asylum. And, in a very special manner, to the res publica and the Spanish Empire. All this based on the continuous background of Mary Magdalene's myth, a fundamental text that unites all the women considered here.
\end{abstract}

\footnotetext{
* Author's address:

Departament d'Història i Història de l'Art

Universitat Rovira i Virgili

Av. Catalunya 35, 43002 Tarragona, Spain

E-mail coral . cuadrada@urv.cat
}

\section{** Author's address:}

La Fondona, fondo documental feminista, queer y LGBTI

Carrer de la Constitució, 25, 08014 Barcelona, Spain 
Keywords: Correspondence, Luisa de Carvajal, Magdalena de San Jerónimo, relics, bodies, myth of Mary Magdalene.

Resumen. El análisis de la correspondencia entre dos aristócratas del siglo XVIXVII -Luisa de Carvajal, Magdalena de San Jerónimo- nos permite reflexionar sobre el valor de las reliquias y su relevancia en la barroca Contrareforma española. Vinculamos las ansias de martirio y la exaltación místico-religiosa de Luisa con varias de las dedicaciones de Magdalena - en la Casa de las Arrepentidas, en la Corte flamenca, y creadora de la Casa de la Galera para mujeres públicas y delincuentescon distintos cuerpos y semióticas: el cuerpo enfermo de los hombres, el contaminante de las mujeres públicas; los cuerpos de las vírgenes, de las prostitutas, de las actrices. Estos se conectan con distintos espacios públicos: el prostíbulo, el teatro, la casa de las Magdalenas. Y, de forma muy especial, con la res publica y el imperio. Todo ello apoyado sobre el trasfondo constante del mito de María Magdalena, subtexto fundamental que aúna a todas las mujeres aquí consideradas.

Palabras clave: Correspondencia, Luisa de Carvajal, Magdalena de San Jerónimo, reliquias, cuerpos, mito de María Magdalena.

\section{Introducción}

A partir de la segunda mitad del siglo XVI Europa conoció un fuerte incremento demográfico y un desarrollo sostenido pero vivió, al mismo tiempo, un período de inquietud, desconcierto y profunda transformación cultural: el mundo había cambiado con la llegada de Colón a América, donde existían pueblos que no conocían a Jesús, y los descubrimientos científicos perturbaron la imagen del universo y de Dios; la iglesia católica del viejo continente parecía quebrar tras la Reforma de Lutero. En julio de 1554, el enviado especial de Carlos I llegó a Inglaterra con la investidura formal de Felipe como rey de Nápoles y duque de Milán; el 25 de julio Felipe se casó con la reina María I de Inglaterra, siendo proclamados: "Felipe y María, por la gracia de Dios, Rey y Reina de Inglaterra, Francia, Nápoles, Jerusalén, Irlanda, Defensores de la Fe, Príncipes de España y Sicilia, Archiduques de Austria, Duques de Milán, Borgoña y Brabante, Condes de Habsburgo, Flandes y el Tirol".

Felipe actuó conforme a lo establecido en el contrato matrimonial, en el que se estipulaba que debía respetar las leyes, derechos y privilegios del pueblo inglés, pero se encontró con una fuerte resistencia por parte de los cortesanos y parlamentarios, llegando incluso a un intento de asesinato, abortado en marzo de 1555 en Westminster (Parker 2010: 125-129). A pesar de ello, ejerció una 
notable influencia en el gobierno del reino, ordenando la liberación de nobles y caballeros presos en la Torre de Londres por haber participado en rebeliones anteriores contra la reina María y, en especial, actuando de forma vital para la reintegración de Inglaterra en la Iglesia católica. El 17 de noviembre de 1558, la reina María I Tudor falleció sin descendencia, ascendiendo entonces al trono Isabel I. Entre el 1535 y el 1559 se reanudó la lucha entre Francia y el Imperio y, con la paz de Cateau Cambrésis, el rey Felipe II adquirió firmeza y estableció la hegemonía española en el ducado de Milán, reino de Nápoles, Sicilia y Cerdeña, dominio que perduró a lo largo de la centuria siguiente. El 4 de agosto de 1578, tras la muerte sin descendientes del rey Sebastián I, Felipe se convirtió, como hijo de Isabel de Portugal, en candidato al trono, que consiguió el 12 de septiembre de 1580.

El siglo XVI estuvo marcado por la crisis religiosa, que alcanzó un punto álgido con la Reforma protestante en 1517 y culminó, diez años después, con la humillación de la Roma papal a través de los mercenarios luteranos al servicio del Emperador. La renovación interna de la Iglesia católica, en respuesta al protestantismo, recogió fermentos procedentes de casi cien años antes, radicalizándolos en una mudanza eclesial que vio su cénit en el Concilio de Trento (1545-1563). Incluso antes de Lutero, de hecho, tanto en España como en Italia, muchos religiosos/as y laicos/as aspiraban al cambio profundo de la Iglesia, influidos por las promesas proféticas y los predicadores que reclamaban el retorno a la pobreza evangélica. Este sentimiento, difundido también mediante la imprenta, se articuló desde varios ámbitos y experiencias.

En los Países Bajos se expandió una corriente de renovación espiritual que se tituló devotio moderna, de la cual su exponente más conocido fue Erasmo de Rotterdam. La necesidad de la reforma individual, que no alcanza en ese momento la discusión de la estructura entera de la Iglesia -como harán más adelante Lutero y Calvino- fue ciertamente advertida por muchos humanistas cristianos, en especial por los círculos de espirituales -los alumbrados españoles o los seguidores de Juan de Valdés, en Italia. Si hasta el fin de los años 40 del Quinientos se dieron tentativas de conciliación de las instancias reformadoras con la política papal, sobre todo en las grandes figuras de Contarini y Reginald Pole, la implacable propagación del protestantismo revirtió todo esfuerzo, provocando una cerrazón total a la regeneración espiritual, desde los años 60 de la centuria. Pablo III (1534-1549) convocó el Concilio tridentino tras el fracaso de la dieta de Ratisbona (1541), por las presiones de Carlos I. El Concilio no encontró vínculos de entendimiento con las instancias 
protestantes, ni tampoco tuvo éxito en lo referente a recomponer el cisma y restaurar la unidad de la Iglesia. Lo que hizo fue reiterar la doctrina general de los siete sacramentos y de la transustanciación, además de introducir decretos disciplinarios destinados a hacer frente a muchos problemas del clero y de la comunidad de los fieles.

Isabel I (1533-1603), quinta y última monarca Tudor, fue reina de Inglaterra e Irlanda desde 1558 (Williams y Fraser 1972). En 1568, el Duque de Alba coordina el aplastamiento de las revueltas protestantes y Felipe II arremete contra la flota pirata de los famosos Drake y Howkins tras lo cual, Isabel temió por la inestabilidad de su reinado; se sumó la Rebelión del Norte y la de Desmond, cuyas consecuencias sumieron a Inglaterra en una posición crítica. Terminó siendo excomulgada por la bula papal de 1570, como consecuencia de su reiterada diatriba anticatólica: "monstruo de mujer, mujer pérfida" la llamará Luisa de Carvajal (Abad 1965: 100-101). La réplica no se hizo esperar e imparangonable fue la especial inquina que mostró la reina contra los católicos leales al Papa, a quienes vetó la misa y obligó a acolitar los oficios de la nueva Iglesia de Inglaterra. Como colofón y como muestra de fuerza, tal vez, hizo ejecutar a la reina de Escocia en 1587, hecho que la blindaría contra un más que probable golpe de Estado orquestado por los seguidores de la Iglesia romana. Tras la sucesión de Jacobo I, casado con la reina católica Ana de Dinamarca, se creyó erróneamente que se relajarían las medidas anticatólicas, pero sucedió lo contrario: se recrudecieron.

El Gunpowder Plot fue un complot fallido, organizado por católicos ingleses para matar al rey Jacobo I y a buena parte de la aristocracia protestante. Querían secuestrar, además, a los infantes reales y provocar un gran levantamiento católico. Salió mal y las medidas anticatólicas, por supuesto, se redoblaron. Es precisamente en esos momentos cuando llega a Londres Luisa de Carvajal, una de nuestras corresponsales de la que, a continuación, vamos a glosar su biografía, en la que incluiremos párrafos de las cartas ${ }^{3}$ que envía a Magdalena de San Jerónimo, antigua amiga y compañera de juegos en las Descalzas Reales en Madrid, quien desde la Corte pasó a Bruselas al servicio de la archiduquesa Isabel Clara Eugenia.

${ }^{3}$ Un grupo muy numeroso de misivas, publicadas en su Epistolario por Abad (1965). 


\section{Luisa de Carvajal y de Mendoza...}

Luisa de Carvajal y de Mendoza (1566/68-1614), vecina de Jaraicejo, Cáceres. Francisco de Carvajal fue su padre y María de Mendoza su madre, ambos pertenecientes a la nobleza. Después de la muerte de su madre fue mandada con su abuela materna en Madrid, donde se rodeó de la más alta ralea. En 1576 se traslada a Soria, junto a su tío materno, el marqués de Almazán, donde recibe una esmerada educación doméstica e intelectual. Junto a la lectura de los clásicos y el latín, Carvajal desarrollará el gusto por la caridad y la devoción cristiana, uno de los pocos espacios donde las mujeres ricas y cultivadas parecían encajar y donde se les permitía producir - por así decirlointelectualmente.

Su pasión religiosa y su amor por los pobres no la abandonarían jamás, y pronto ingresaría en una orden religiosa. Tampoco abandonó el gusto por la literatura y, bajo el amparo religioso, pudo dar rienda a una pluma literaria orientada, sobre todo, a la poesía. Al cumplir los trece años se mudó, sola, a Pamplona, y allí pudo embeberse de obras religiosas que dejaron una amplia huella en su espíritu. A los quince años de edad rechazó la propuesta de matrimonio avalada por la familia para mantenerse muy firme en su deseo de servir únicamente a Dios y amparar a los pobres, un rasgo de su carácter que la acompañaría, literalmente, hasta la muerte. Por supuesto, correlativamente, un deseo inapelable de martirio hacía mella en Carvajal.

... cuando vuestra merced estaba en España, yo mudé de resolución; y no ve, cierto, que ésta de venir aquí [Londres] estaba en mi pecho desde los 18 años de edad, aguardando abriese Nuestro Señor camino; y no osaba decir a vuestra merced por algunas causas que me hacían callar con mis muy amigos. (Abad 1965: 165 [22.03.1606]).

En un manuscrito acerca de su vida espiritual -que más adelante, en la víspera de su viaje a Inglaterra, dirigirá a su confesor- Luisa no llega a explicar claramente qué sucedió con su tío, pero alcanza a mostrar que el marqués la sometió a sádicas penitencias.

Tras la autorización de su tío, Carvajal inicia su vida independiente. Con solo 26 años deja atrás la idiosincrasia noble y convierte su casa en una suerte de beaterio. Visitaba a mujeres hospitalizadas, rezaba por ellas y les brindaba cuanto necesitaran. Atendía a las pobres pecadoras con el ánimo de obtener confesión y no abandonaba el vestido de monja ni siquiera en su propia casa. 


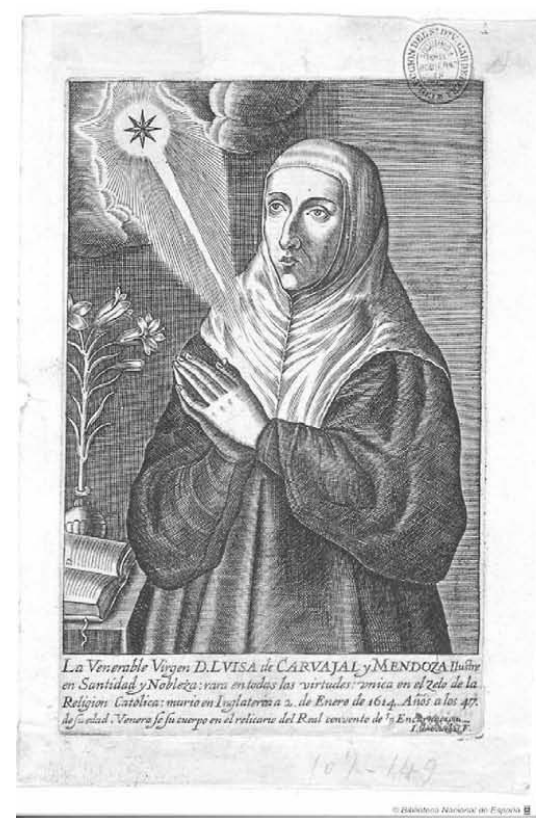

Fig. 1. Juan de Courbes: Retrato de Luisa de Carvajal y de Mendoza (1623).

Alcanzó los cuatro votos, pobreza, obediencia, perfección y martirio, entre 1593 y 1598. Sin embargo, no quiso renunciar a su herencia, incluso llegó a los tribunales para reclamarla, pero con el único ánimo de convertirla en obras caritativas. Tras la ejecución en Inglaterra del jesuita inglés Henry Walpole, decidió dedicar su fortuna a la creación y mantenimiento del Colegio Inglés de Jesuitas en Lovaina.

...habiendo sabido, días ha, que una doncella llamada Margarita Valpolo, hija de un caballero principal de Inglaterra y hermana del glorioso mártir Enrique Valpolo, de la Compañía, quiere ser religiosa y está con mucho desamparo en aquel reino, he deseado con extremo traella a mi compañía... (Abad 1965: 127 [25.01.1603]).

En 1597, recibió permiso de su confesor para recibir la comunión a diario, algo muy inusual entonces. En 1598 escribió: "Procuraré, cuanto me sea posible, buscar todas las ocasiones de martirio que no sean repugnantes a la ley 
de Dios". La idea del suplicio no era solo suya, la compartía con San Jerónimo y otros, como se deriva de una carta dirigida a Magdalena:

La relación de su letra del martirio de la santa Marta han tenido hasta ahora en el colegio inglés, y yo la vuelvo a vuestra merced porque me lo manda; y no pienso me hago menos en obedecerla en esto que vuestra merced hizo en hacerme merced de enviármela. (Abad, 1965: $121[24.08 .1602])$.

Fue este su periodo más productivo y, tal vez, brillante, de su producción literaria, aunque solo se conserven cuarenta y ocho poemas. El carácter religioso no lo abandona en ningún momento: es a través de él que podemos llegar a comprender esta figura histórica, su pensamiento, la mentalidad de la que bebe, su devoción por las reliquias y su fidelidad a la causa católica. Es a través de sus cartas que descubrimos cómo sus sacrificios en vida por el amor a Dios la llevaron a contraer muchas y muy violentas enfermedades, hasta que -demasiado tarde- renunció al experimento de ser pobre.

Algunas veces, considerando el ánimo que siento en el corazón, que es extraordinario, y viéndole encerrado en el pecho de una mujer flaca, me admiro y no entiendo las trazas de Nuestro Señor acerca desto, pues su mesma mano fue la que crió el corazón y ánimo robusto y el cuerpo en que le puso, flaco y retirado en un rincón (Abad 1965: 110 [29.01.1600]).

... la Santísima Virgen Vulnerata [...] cada día me presento ante ella, aunque esté muy mala y me levante para solo ir de la cama, como lo he hecho estos días, que lo he estado harto; y aunque quedo mejor, me es necesario estar todo el día sobre la cama (Abad 1965: 116 [11.01.1602]). ${ }^{4}$

Tuve una calentura continua tan recia que me consumió a los seis días toda la carne del cuerpo con una fuerza y violencia extraña; y decían los médicos que más parecía calentura de algún muy robusto pastor que de quien no lo era. Tuve grandes cámaras de sangre que no pensaban que tenía yo tanta, ni suelo ser sujeta a sangre, antes suele parecer que tengo poca. Quedé tan flaca de esto y del hastío que, después de buena, no me he podido levantar en muchos días, ni

${ }^{4}$ Nuestra elipsis. 
ya vestida salir al suelo, ni andar un solo paso, ni tenerme sobre los pies, aunque fuese con ayuda de mis compañeras. (Abad 1965: 128 [25.01.1603]).

Es en esta época cuando interesa a Magdalena de San Jerónimo por los seminarios ingleses y trata, en varias cartas, de la fundación de un convento:

Dígale vuestra merced a su Alteza [la archiduquesa Isabel Clara Eugenia] que si gustará de que le vaya a hacer un monasterio de españolas a mi costa; que me dicen holgó mucho con uno de señoras inglesas que se ha fundado de poco acá en esa corte, hija una de ellas del gloriosísimo Tomás Percy, mártir, conde de Northumberland. (Abad 1965: 100 [16.03.1600]).

El celoso seguimiento de sus litigios monetarios la llevó, en 1601, hasta Valladolid, en donde acababa de afincarse la Corte:

Sepa vuestra merced que nos dicen por muy cierto que se va la Corte a Valladolid, para mayo o poco después, y habré de ir yo a acabar mi pleito forzosamente, adonde me acordaré harto de vuestra merced y veré su casa y a su hermana doña Juana. (Abad 1965: 102 [16.03.1600].

Le escribe puntual cuando va al convento de Magdalena:

He ido a ver su casa de vuestra merced, y para eso atravesé todo el lugar con tanto gusto, que pocas hiciera en su género con más. Estaba la iglesia sola y acabando de hacer oración al Santísimo Sacramento y a la Virgen de la Esperanza (que es devotísima, y me acordé allí harto de vuestra merced), volví la cabeza y vi en las celosías dos religiosas; y llegándome a ellas, me empezaron a hablar muy amigablemente, diciendo que habían oído su nombre de vuestra merced cuando llamamos a la puerta, que estaba cerrada, mostrando tenerle gran respeto y amor. (Abad 1965: 114 [10.09.1601]).

Viajó a Inglaterra buscando el martirio, consciente de la terrible persecución que sufrían los católicos en tierras anglicanas. Gracias a su perseverancia, el proceso entablado por su herencia fallaría a su favor, lo que le permitió legar 
todos sus bienes a la mencionada misión suicida, y partir, convencida, hacia la isla.

Esta carta se queme luego suplico a vuestra merced, a quien en confesión y sumo secreto fío este negocio, que está escondido en mi corazón, y no me conviene lo sepa criatura viviente hasta estar allá; y así mi partida ha de ser muy encubierta, para lo cual me saldré de aquí a otro lugar, que no habrá persona que pregunte por mí... (Abad 1965: 138 [16.11.1603]).

Llega a Londres en el peor momento, el de la conspiración de la pólvora. La primera carta que envía Luisa a Magdalena es desde Londres, en diciembre. Los primeros meses los vivió a salto de mata, y quiso pasar tan oculta que no le debió ser posible escribir a nadie.

Y en cuanto a mí, señora, digo que el designio que me sacó de España principalmente, me metió en esta selva espesa de fieras; y hasta haber satisfecho a lo que aquello pide [el martirio], no hallo camino para la vuelta. (Abad 1965: 150 [14.12.1605]).

Entonces ya la habían obligado a refugiarse en la embajada española, donde el embajador español Alonso de Velasco la tuvo bajo su protección. Para llevar a cabo su clandestina labor misionera -"al servicio de Dios y de la Sagrada Virgen"- aprendería, no sin esfuerzo, el idioma inglés.

Estoy siempre con ellas [dos compañeras] sola, cerrada mi puerta con llave y hablando en su lengua, porque no saben otra ninguna; y como no sea contar historias, puedo hacerlo razonablemente en cosas ordinarias, y aunque con cortedad de razones, puedo hablarlas en Nuestro Señor muchas veces y me entienden. . (Abad 1965: 160 [02.03.1606]).

El primer día de mayo de 1606 es recibida en Londres por el reverendo padre Enrique Garnet, superior de los jesuitas destacados en Inglaterra, quien se espanta ante la firme voluntad de procurarse el martirio que manifiesta a las claras doña Luisa. Pero sus desesperadas recomendaciones de discreción, serenidad y prudencia no echan raíces en el alma entusiasta de Luisa, que 
emprende de inmediato un público y continuo hostigamiento contra el protestantismo de sus forzosos anfitriones: se enfrasca en agrias discusiones con los más fanáticos defensores de la herejía anglicana, realiza frecuentes y ostentosas visitas a los católicos recluidos en las cárceles por causa de su fe:

Otros muchos amigos están presos; dellos apretados y dellos en cárcel donde pueden ser visitados, y sin hierros. Yo fui la semana pasada a una do hay seis [...] Yo fui derecha, sin ruido ni ver gente, a la sala donde los seis [sacerdotes] tenían su estancia, y otros católicos que yo conocía ... (Abad 1965: 160 [02.03.1606]).

El otro día pensamos tener un mártir nuevo, que fue un sacerdote que de nuevo condenaron a muerte, señalando la hora de las siete $u$ ocho de la mañana siguiente. Y aquella noche, tarde, se hizo diligencia [...] madrugué y fuime delante la puerta de la cárcel; y porque mi flaqueza es mucha y el concurso de la gente era grande, quedéme sentada en un tablón de una tienda, desde donde con mi compañera estuve viendo bajar trece o más delincuentes y atar en los carros. $(\text { Abad 1965: } 223[31.07 .1607])^{5}$

Desgarra públicamente los carteles antipapistas que los ingleses tienen colgados en sus vías y establecimientos, y promueve, sin temor ni fatiga, cuantos disturbios y altercados puedan difundir su nombre y alertar de su presencia evangelizadora en la isla. Tanto afán no le merma de informar a su amiga de las noticias importantes que acaecen en Londres, como del estado endémico de la peste, amén de otras enfermedades:

De lo que es la peste, ahora no hay memoria, porque los mayores trabajos han hecho olvidar ese tan grande. Cuando empezaron se tenía por mejoría no morir de varios males más de ciento cada semana; y de peste no más de treinta en algunas. Todavía dura, según me dicen, pero debe ser mucho menos. Aunque ha estado cerca de donde he vivido y de mi misma ventana, nunca ha tocado casa nuestra, a Dios gracias... (Abad 1965: 155 [02.02.1606]).

La peste crece más estos días, que está ya vinculada doce años ha, según afirman; y poca o mucha, nunca falta. ¡Qué lindas gracias tiene Inglaterra, que no le faltaba, cierto, sino ésta para echar el sello! (Abad 1965: 191 [12.09.1606]).

${ }^{5}$ Nuestras elipsis. 
En 1608 es encarcelada en Londres por vez primera, de resultas de una violenta disputa que sostiene con una tendera anglicana, que la había acusado de no ser mujer:

A la señora de la tienda no le era tolerable y incitaba a los otros contra mí, diciendo era lástima que me sufriesen, y que yo no era mujer, sino algún sacerdote en hábito mujeril, para con eso ir persuadiendo más fácilmente mi religión por las calles. (Abad 1965: 251 [s.f.]).

El embajador del rey de España cerca de Londres consigue la excarcelación de doña Luisa después de que ésta haya pasado cuatro días entre rejas, pero no logra disuadirla de esa fervorosa persecución de su propio aniquilamiento: al poco tiempo de haber quedado libre, emprende la campaña de recoger los miembros amputados de los católicos ejecutados por descuartizamiento, despojos que ella misma adecenta y guarda amorosamente en cajas de plomo, para reverenciarlos como reliquias sacras. Veinte condenados católicos gozaron de un banquete que ella misma organizó antes de que fueran ajusticiados, sucedió a finales de 1610 en la prisión de Newgate. Todos ellos fueron descuartizados días después, y Carvajal consiguió atesorar un dedo de John Roberts, un monje benedictino católico de sobrada reputación que trabajó como espía en Inglaterra -fue canonizado por el papa Paulo VI en 1970.

Poco tardaría Carvajal en ingresar en prisión acusada de espía, como tantos otros fieles al catolicismo lo habían sido con anterioridad. Debido a la alcurnia de nuestra protagonista, el conflicto diplomático estaba garantizado, y tuvo que intervenir el embajador español para que fuera liberada, pero esta vez Felipe III dictó una orden que la obligaba a regresar a España. Muy enferma, aceptó, pero moriría poco tiempo después, el 2 de enero de 1614, antes de hacerse efectiva la orden de regreso. Sus restos sí que volvieron a España al año siguiente. Y fue precisamente Magdalena de San Jerónimo, junto con el obispo de Mondoñedo, don Pedro Fernández Zorrilla, quienes se encargaron oficialmente de recoger el cadáver de su amiga en el monasterio de Portaceli, de Valladolid. Felipe III ordenó que fuera enterrada en el Real Monasterio de la Encarnación de Madrid, donde se venera aun su relicario. 


\section{Desde el principio del Quinientos...}

Desde el principio del Quinientos algunos de los factores de equilibrio que regían las sociedades europeas empezaron a resquebrajarse, cambiando lentamente la sensibilidad colectiva. Las capacidades de absorción de la economía ciudadana se debilitaron. Aumentó de forma drástica la diferencia entre salarios urbanos, relativamente altos, y los rurales, atascados a pesar del crecimiento demográfico. Ello comportó una migración elevada de pobres y desocupados hacia las ciudades y a la consiguiente erosión progresiva de los salarios, además del aumento de los precios de los productos de primera necesidad. A fines de la centuria, las gentes que no lograban vivir de los propios recursos fueron cada vez más numerosas, y una oleada de pobres, indigentes, vagabundos y necesitados invadieron las urbes. Especial relevancia reviste para el tema de nuestro estudio el cambio de percepción social ocurrido respecto a esta franja de población: en toda Europa, la opinión con respecto a la pobreza se dislocó completamente, llegando incluso a producirse una inversión de las medidas políticas y asistenciales defendidas con anterioridad.

Teresa de Carvajal puede ser leída como la ulterior pobre que quiso vivir según las máximas religiosas de una Iglesia que ya no existía. Ante el cisma protestante, ella redoblaba el sentido mendicante que otrora numerosas órdenes religiosas católicas habían defendido y que, tal vez, servían de claro contrapunto al protestantismo. Castidad, obediencia y pobreza, fueron el lema heredado de las carmelitas descalzas. Pero Teresa de Carvajal no solamente quería erigirse como adalid de pobreza, obediencia y castidad; fue, por un lado, indirectamente crítica con su propia Iglesia que lejos estaba ya de predicar con el ejemplo y, por el otro, señaló muy a las claras la irremisible tensión entre la palabra del hombre y la de Dios, entre las razones de estado y las religiosas.

Y cómo persuade el demonio esto tan cuidadosamente, a los necios con razones groseras, ya los de buen entendimiento, con unas tan sutiles, que basten a dejarlos ciergos y engañados y enredados en millares de pecados mortales en diversas materias [...] con olvido de aquel que los crió y redimió con su sangre. [130] Y lo que temo es no vengan a pasar el pie delante a las cosas de la gloria de Dios las razones de Estado. [...] A los que amo, digo a nuestros amos, de ahí y de allá, libre Dios, por su misericordia, de tales razones de Estado. (Abad 1965: 164 $[22.03 .1606])^{6}$.

${ }^{6}$ Nuestras elipsis. 
Paradójicamente, su propia vida se convirtió en una razón de Estado, por tener sangre noble y por provocar casi un conflicto entre dos países que trataban de limar ya sus asperezas. Carvajal puso su cuerpo al servicio del Dios más católico, desobedeciendo incluso a las máximas autoridades civiles. Ella ve en el gobierno humano de los Estados modernos la pérdida de la obediencia religiosa.

Y no por propio negocio, cierto, sino por el de la gloria de Dios y amor tierno que tengo a nuestros amos y deseo de sus buenos sucesos; para los cuales es el llano camino dar gustos a Dios, aunque sea disgustando a los hombres que se desean conservar en amistad por causas de Estado. (Abad 1965: 177).

El cuerpo como primera y última instancia de lo humano, dueño indisoluble que puede resistir a la tortura y de quienes Carvajal recogerá los trozos de carnes, las reliquias de los pobres santos, a la manera de un capital sacro con el que se comerciará la reputación de la fe y de la iglesia. Pero la ordenación civil y el cambio de valores de la época parecían avanzar sin una oposición suficiente: el/la pobre no era ya la imagen de Cristo, ni el medio a través del cual se podía ejercitar obras de caridad, como había sido común en el Medievo. Los indigentes se convirtieron en una amenaza peligrosa al orden constituido, entendidos con frecuencia como responsables de su propia condición subalterna. Las masas de miserables empezaron a ser expulsadas; se desarrollaron nuevas políticas para asistir a la invalidez e infancia huérfana, mientras que, al mismo tiempo, se aislaba y recluía a las personas pobres, ociosas y no productivas. El siglo XVI vio, por tanto, el nacimiento de instituciones nuevas que unían el fin filantrópico -asistencial al del control, y la represión de sectores concretos de la sociedad. La expresión intelectual más famosa de esta nueva política coercitiva se encuentra en la obra de Juan Luís Vives (1525):

Los mendigos vagos, sin domicilio cierto, que están sanos, digan sus nombres y apellidos delante de los jueces y gobernadores, y al mismo tiempo la causa que tienen de mendigar, pero sea esto en algún lugar ó plaza patente, para que no entre semejante chusma à la casa ó sala del tribunal ó gobierno; los enfermos hagan lo mismo delante de dos ó cuatro comisionados con un médico, para que todo el Congreso no tenga que ocuparse en verlos, y pidaseles que manifiesten quién los conoce que pueda dar testimonio de su vida. A los que eligiere el 
gobierno para examinar y ejecutar estas cosas déseles potestad para obligar, compeler y aun poner en prisiones, para que puedan conocer los jueces del que no obedeciere. (Vives 1525: 107)

Al mismo tiempo, se difundía una moral más severa, si cabe, respecto a las mujeres. La Iglesia católica emprendió con energía el proyecto contrareformista a fin de reordenar y disciplinar las costumbres sociales; reforzó los vínculos de las prescripciones que delimitaban la condición femenina y agudizó el código moral impuesto a las mujeres. La normalidad femenina consistía en seguir obligatoriamente las pautas marcadas por los usos y costumbres, y en obedecer las reglas sociales. Esta sociedad normativa del Antiguo Régimen atribuía un ambivalente valor a la subjetividad y/o a la individualidad, hombres y mujeres habían de seguir las vías preestablecidas, predefinidas por las condiciones de nacimiento, género, estamento social y oficio familiar; una uniformización del individuo a partir de parámetros rígidos, acompañada por una observancia atenta de las conductas individuales. Uniformización que implicaba una visibilización de la disidencia de corte individual como no había sido posible imaginar con anterioridad. Las vidas de las mujeres debían ser más predecibles que las de los hombres, sus posibilidades en cuanto al futuro estaban muy bien delimitadas bajo un patrón familiar marcadamente androcrático.

La división sexual de los roles imponía, ya a las mujeres, ya a los hombres, determinados comportamientos -dominación y acción masculinas frente a castidad y sumisión femeninas. Toda mujer había de mantener un papel preciso en el seno social, y debía ser controlada - la virgen protegida e inviolada hasta el matrimonio; la casada fiel y obediente al marido. Se buscaba de cualquier modo no dejarles ningún espacio de decisión autónoma o de elección independiente del propio destino. La mujer no podía ser dueña de sí misma, había de estar, por fuerza, inscrita en un rol preestablecido, fuera del cual no había ninguna otra posibilidad. Quien exponía la voluntad de decidir sobre el propio destino espantaba y era reprimida. La individualidad sujeta producía sujetos punibles.

Carvajal parece tener también una opinión formada al respecto de esa subyugación femenina al cuerpo social masculino, y se lo dice a San Jerónimo en 1603; evidentemente, desde idénticas razones religiosas, pero con determinación y fuertes argumentos, Carvajal advierte que esa subordinación impide la obediencia directa de la palabra divina y garantiza la proliferación del pecado por la creación de intermediarios entre Dios y la mujer: 
$\mathrm{Y}$ ¡qué poco haré yo en ponerme en este viaje por el gusto de Nuestro Señor y su santísima voluntad!, pues por seguir a una criatura mortal y perecedera hacen eso y más cada día tantas mujeres, con menos fuerzas que yo o pocas más, siguiendo a sus maridos, padres o amos, cuya providencia es tan flaca y incierta; y a todos les parece bien aquello; y mucho mejor, si, acaso, por ir allá o más lejos, se supiese que habían de adquirir o alcanzar alguna gran honra o seis u ocho mil ducados de renta, con lo cual a ningún amigo o deudo habría que no lo aconsejase. Y por lo que es tanto más, sé que muchos me contradirían, mayormente los que pensasen que con mi ida perdían algún interés. (Abad 1965: 138 [10.11.1603]).

A lo largo del siglo, en particular en los reinos católicos, se hizo aún más fuerte la preocupación por la moralidad y las condiciones de las mujeres solas, las irregulares, en los márgenes, como las vagamundas y las chicas desarraigadas que proliferaban, cada vez más, en las ciudades, inconveniente que era, a la vez, sentido para el ethos religioso y moral de la época (Amussen 1985: 271). La prostitución, percibida en el período medieval como mal necesario, fue cada vez menos tolerada y, paulatinamente, criminalizada. El control de las mujeres irregulares se hizo más común y severo mediante la creación de un aparato de instituciones y tribunales canónicos que actuaban contra la violación de la moralidad. La puta era enteramente puta hasta que no pasara por un proceso de expiación largo y sitiado.

Para ilustrar la noción de mujer que se tenía en esa época, y no precisamente de las marginales, sino de todas sin distinción, podríamos citar infinitud de textos, pero no hallaríamos diferencias señalables. Bastará con detenernos en la opinión del Tesoro de la lengua castellana o española (1611), de Sebastián de Covarrubias, donde encontramos a la mujer no tanto como el opuesto al hombre sino como el resultado de nudos etimológicos. En palabras de nuestro ilustre lexicógrafo: "Del nombre latino mulier, a molitie (ut inquit Varro) inmutata et detracta litera, quasi mollier, et propie mulier dicitur quae virgo non est'. El circunloquio erudito en latín es concluyente: mujer es "la que no es virgen". Lo demás, lo deja al albur de una enciclopedia de infamias: "Muchas cosas se pudieron dezir con esta palabra; pero otros las dizen, y con más libertad de lo que sería razón". Y tanto: la entrada enciclopédica se extiende en toda la serie de improperios misóginos de la patrística y de las llamadas autoridades clásicas, desde San Máximo hasta San Maquino, desde Diógenes y Demócrito a Marco Aurelio: "naufragio del hombre", "embarazo del sosiego", 
"daño continuo", "fiera doméstica", "disfraçado veneno" y "mal necesario". La mujer no se opone al hombre, no es parte de una dicotomía -como hoy-, se trata de un continuo entre dos extremos del mismo significante, donde hombre encarna todo lo atinado, racional y fuerte y la mujer la versión desmejorada de lo humano. Siendo ésta la concepción de toda mujer, no es de extrañar que a las consideradas peores de todas ellas se las quemara en la pira: la formación del Estado Moderno exigió la exterminación de toda disidencia (Federici 2004, 78-84).

Es en este contexto histórico donde vivió Magdalena de San Jerónimo. ¿Cuesta creer que su legitimidad naciera de las palabras de "mujer contra mujer"?7 ${ }^{7}$ No.

\section{Magdalena de San Jerónimo...}

Magdalena de San Jerónimo es un personaje clave para la historia de la penología, una mujer bisagra que adaptó los esquemas de una vieja institución para diseñar las primeras cárceles destinadas a la rehabilitación, desplazando la privación de la libertad entendida como mero preámbulo del suplicio a su identificación. Esto nos obliga a detenernos en ella, no tanto por tratarse del sujeto mínimo de la fenomenología histórica, no para asignarle un poder desmedido sobre el curso de los acontecimientos, ni para encumbrarla o acusarla, sino simplemente como instancia privilegiada que fue testigo y objeto de una interpelación histórica de nuevo cuño.

Magdalena de San Jerónimo, cuyo nombre original era Beatriz de Zamudio, nació en la segunda mitad del siglo XVI y vivió probablemente hasta la tercera década del Seiscientos. Su familia provenía de la casa de los Zamudio, en el reino de Vizcaya, y tanto su padre como su abuelo sirvieron militarmente a la Corona y fallecieron habiendo obtenido los rangos de capitán y coronel de Carlos V y Felipe II, respectivamente (Lakarra 1992, 175). No queda claro

\footnotetext{
${ }^{7}$ Bajo el axioma de una pretendida solidaridad entre las miembros del género femenino, se ha discutido acerca de la posición de San Jerónimo con respecto a sus congéneres, las mujeres. Eukene Lacarra publica un artículo con el título "¿Magdalena de San Jerónimo: muger contra mugeres?", olvidando un contexto histórico que hacía incompatible el reconocimiento público y la existencia de mujer, si no era en connivencia con la postura oficial, claramente opuesta a la autonomía y relieve de las mujeres en tanto que mujeres.
} 
si Zamudio nació en Valladolid, pero sí que se declaraba vallisoletana, y que muchos de los textos que la mencionan se refieren a ella como vecina de la ciudad. Sabemos que fue una mujer con numerosos contactos de altísima ralea, cuya influencia en los menesteres civiles dejó una impronta fundamental en la ordenación penal del reino. Con el traslado de la Corte de Felipe III a Valladolid, Zamudio adquirió una mayor influencia política. Fue el duque de Lerma quien presionó para que la capital del reino se trasladara de Madrid a Valladolid durante cinco años. Y fue el mismo rey quien recibió el tratado que San Jerónimo redactó para convencerlo sobre la necesidad y conveniencia de encerrar a las malas mujeres.

Como manifiesta Margarita Torremocha (2014), se trata de "un personaje conocido y desconocido a la vez", tal vez mal averiguado o en vías de redescubrimiento. Esto se explica por el desinterés habitual en la historia que atañe exclusivamente a las mujeres, a la poca documentación conservada -aunque esto puede ser consecuencia de lo primero- y, asimismo, quizás, al olvido y confusión de las instituciones que dirigió. En muchas ocasiones aparece su nombre acompañado de distinciones religiosas como la de sor Magdalena o la de madre Magdalena, aunque no parece haber ningún apoyo documental que sostenga su adscripción oficial a la iglesia. Algunas fuentes la consideran religiosa bernarda, otras terciaria, beguina, o tal vez monja; hay quien sugiere no fuera ella misma una magdalena arrepentida (Barbeito 1991: 37; Perry 1992: $145-170)$.

De lo que no cabe duda es que sus acciones la colocaron en una posición privilegiada a ojos católicos. Verbigracia, ayudó económica y políticamente a la carmelita Madre Ana de Jesús, compañera de Santa Teresa de Ávila y fundadora de las Descalzas en Francia y Bruselas. Puede que, a falta de una distinción clara, ante la ausencia de tratamientos específicos para las mujeres, se optara por uno religioso, por ser estos abundantes y bien reconocidos. Otra hipótesis, que debería contrastarse debidamente, es que sean alusiones a su cargo como fundadora y directora de casas correccionales y de penitencia donde, a menudo, sus dirigentes eran llamadas madres o padres. Esto ocurre también, aunque paradójicamente, en el caso de las mancebías, donde las madres y los padres eran los regentes de los prostíbulos y encargados de su gestión. La tipología jurídica y/o religiosa de estas casas correccionales no tenía una adscripción clara, y menos aún en la Modernidad, tiempo en que muchos de los centros de reclusión bailaban entre el poder eclesiástico y el civil. 
No por azar o casualidad Beatriz toma el nombre de Magdalena, y de Zamudio pasa a San Jerónimo. Cuando Felipe III trasladó la corte a Valladolid movió consigo a ciudadanos/as de toda clase y condición: las prostitutas ampliaron en gran número la población ya existente. En 1573 nuestra protagonista había fundado en el campillo de San Nicolás una casa Pía bajo la advocación de Santa María Magdalena, que pasó a llamarse Casa Pía de la Aprobación o de Santa María Magdalena, regida y administrada por la Cofradía de Santa María Magdalena y tutelada por el Duque de Lerma, donde las prostitutas arrepentidas eran recogidas y adoctrinadas para recibir el hábito en San Felipe de la Penitencia ${ }^{8}$ :

Y porque en esta villa se ha fundado y elegido la casa pía de Santa María Magdalena, en la parroquia de san Nicolás, regida y administrada por la cofradía de Santa María Magdalena, que por yndustria de Magdalena de san Gerónimo se a fundado, a donde se recojen las mugeres herradas yncontinentes; nos a parecido de conformidad que se nombre y señale la dicha casa ara que en ella estén y sean recojidas las dichas mugeres y biban en ella, según sus constituciones de la dicha casa y cofradía [...] para que desde allí bayan al dicho monasterio de san Phelipe a recibir el ávito y profesión de monjas. (Canesi Acevedo 1996: 234$)^{9}$.

Hacia 1588 Magdalena de San Jerónimo era la administradora de esta casa, que ella misma reformó, legándole, además, su herencia, sus más preciadas reliquias y la obtención de ciertos privilegios reales, con el fin de garantizar a perpetuidad su supervivencia financiera. Ya en una homilía del papa Gregorio Magno († 591) se muestra a la María Magdalena evangélica como prostituta arrepentida; por eso, la leyenda que la acompaña hace que pase el resto de su vida en una cueva en el desierto, haciendo penitencia y mortificando su carne, siendo frecuentes en el arte las representaciones de la Magdalena penitente, acercándonos el adjetivo al título de las casas de reclusión de casas de Penitencia. La imagen de penitente puede derivar también de la tradición de María Egipcíaca, santa del siglo V, quien según Rutebeuf (2006), es uno de los ejemplos más notables de conversión y de expiación de toda la historia

${ }^{8}$ Así se define en una certificación realizada en 1597, a petición de Magdalena de San Jerónimo, del documento realizado en 1589 por Magdalena de Ulloa. Archivo Histórico Nacional (en adelante AHM), Clero, Legajo 7.844.

${ }^{9}$ Nuestras elipsis. 


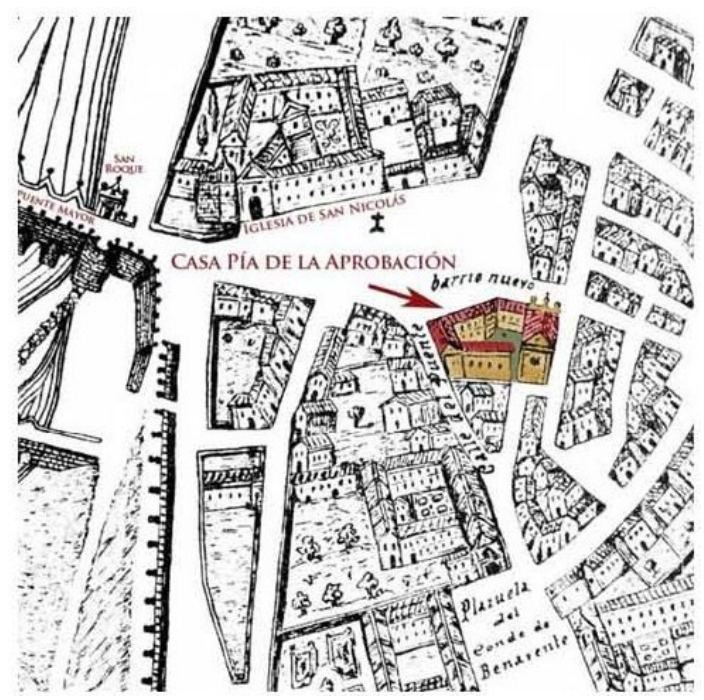

Fig. 2. Casa Pía de la Aprobación.

cristiana. También meretriz que inspira otro de los nombres por los que se conocen estos lugares: de arrepentidas, de egipcíacas. Por lo tanto, que Beatriz escoja llamarse Magdalena refleja un compromiso vivencial sin fisura.

Respecto al apellido que adopta nos encontramos, de nuevo, ante un acto de profundo carácter simbólico. San Jerónimo, padre de la Iglesia, nació en Estridón (331-347). Dedicó su vida, por entero, al estudio de las Sagradas Escrituras. Después de un tiempo de mortificación, Jerónimo se convirtió en guía espiritual para un grupo de mujeres aristocráticas de Roma, con la intención de conducirlas por el camino de la perfección evangélica, esto es: el abandono de las vanidades del mundo y el desarrollo de obras caritativas. Sobre las relaciones físicas entre hombre y mujer, el santo creía, como cabía esperar, que debían ser rechazadas por completo. El tipo de placeres que proveían debían considerarse pecaminosos e ilícitos, aunque se produjeran dentro del matrimonio: "El hombre prudente debe amar a su esposa con fría determinación, no con cálido deseo [...] Nada más inmundo que amar a tu esposa como si fuera tu amante" 10 .

${ }^{10}$ Nuestra elipsis. 
Vulgata, de vulgata editio -edición para el pueblo-, fue el nombre con que dio a conocerse la traducción que San Jerónimo el Santo hizo de la Biblia y que, tras su publicación en el siglo IV, fue declarada por el Concilio de Trento (1546) como la única, oficial y auténtica traducción para la iglesia Latina (Sigüenza 1853: 253-279). Razones no le faltaron, pues, a Zamudio, para convertirse en San Jerónimo, a pesar de no entrar en convento de jerónimas nunca. Pero no pensemos que Magdalena era única en su especie, sino al contrario, debemos comprender esta semiología como una enunciación moral con pleno sentido epocal y, con toda seguridad, adoptado por muchas otras mujeres. Honor, honra y honestidad debían ser demostradas continuamente en una época en la que la observancia sobre las costumbres y las buenas formas cobraba un rango crítico.

El tratado que escribió Magdalena de San Jerónimo se conoce con el título completo de Razón, y forma de la galera y casa real, que el rey nuestro señor manda hazer en estos reynos, para castigo de las mugeres vagantes, ladronas, alcahuetas, y otras semejantes, redactado en la primera década del Seiscientos. Con él dio forma en España, en un sentido político, al encierro humanista. Combinó el suplicio con la reclusión entendida como castigo en sí misma, llegando a precisar el trato que debían recibir las reas, conforme a la desobediencia/delito/pecado al que hubieran incurrido. Los argumentos que esgrimió en favor del castigo de las mujeres deshonestas, pecadoras y delincuentes guardaban, a su juicio, una proporción directa con la corrupción de la república.

Que fueran cárceles para mujeres las primeras formas de encierro como fin en sí mismo es, quizás, lo que las convierte en instituciones poco conocidas por aquellas autoras/es que se han centrado en la historia del encierro; Elisabet Almeda (2002) lo confirma en su libro Corregir y castigar, en el que, acertadamente, señala las galeras femeninas como auténticas precursoras de la concepción de la pena centrada en la privación de la libertad y la disciplina, uno o dos siglos antes de lo que Foucault sostuvo en Vigilar y castigar. Tampoco Melossi y Pavarini (1982), los otros grandes referentes de esta historia, parecen darle un lugar demasiado privilegiado a las galeras femeninas: en su lugar, se centran en el análisis marxista de las casas de trabajo e ignoran la especificidad femenina del confinamiento.

Sin embargo, lo que Almeda y otras/os ignoran es el papel que tuvieron las casas de las Arrepentidas dentro de este renglón de la historia que suelen poblar las mujeres, y cuyo impacto sobre la sociedad en general suele obviarse. 
San Jerónimo había dirigido durante años la Casa de las Arrepentidas en Valladolid, como hemos señalado. Se trataba de una institución nacida en la península probablemente dos siglos antes, en el s. XIV, de cuyo acervo y experiencia propia extrajo la pericia necesaria para elaborar y defender una gestión y organización carcelaria dirigida exclusivamente a mujeres. Y no una cualquiera, sino una con la capacidad de sostenerse a nivel nacional. Aunque San Jerónimo popularizó este importante escrito y tradujo su experiencia como directora de la Casa Pía de la Aprobación, no fue tampoco la ideóloga primera. Parece que Pérez de Herrera ${ }^{11}$ (1598) había publicado ya años antes un tratado en el que se exhortaba a las instituciones civiles a crear un modelo de pena específico para las capacidades y especificidades femeninas. San Jerónimo lo plagió parcialmente en su Razón y forma ... y, gracias a su influencia política, lo popularizó y sirvió de base para su posterior implantación. Discurso de amparo de los legítimos pobres y reducción de los fingidos lleva por título la obra de Herrera, dentro de la cual encontramos el siguiente fragmento, con el que, tal vez, se resuma perfectamente uno de los principales argumentos que Zamudio dio en su popular escrito:

El remedio y traza es que, pues hay caminos para ocupar por formas diferentes en estos reinos de V. M. a los vagabundos, castigándolos a ellos, y a los delincuentes por los delitos que cometen, escondiéndolos y ausentándolos de las repúblicas, para que no hagan más perjuicio en ellas, haciendo que escarmienten y paguen lo que han hecho, y que otros con el ejemplo no se atrevan a cometer delitos semejantes, poniéndolos a todos en aprieto y concierto, sirviendo a Dios y a V. M. en sus galeras o minas de azogue, parece que también es razón, y justo, mandar V. M. que haya en ellos algunas reclusiones, y castigo moderado, para las mujeres vagabundas, perdidas y delincuentes, conforme a su flaqueza, que corresponda a esto $^{12}$.

La conciencia de nación fue ganando terreno conforme avanzaba la Modernidad y, con ella, quedó aparejado un ideal de república que daría progresivamente forma a un Estado moderno. Por eso, las instituciones penales ante-

${ }^{11}$ Protomédico de las Galeras de España durante 12 años, además de militar, poeta y político. Después de su faceta como médico militar se dedicó a distinguir entre los verdaderos y falsos pobres, aunque no sabemos si se reconoció a sí mismo como uno u otro tras morir en la pobreza, según relatan sus biógrafos.

${ }^{12}$ Cursiva en el original; ortografía adaptada al castellano moderno. 
riores, aunque existiera cierto hilo de continuidad, suelen aparecer de forma disímil, desordenada, asincrónica y con una regulación no generalizable, además de dejar un rastro difícil de trazar historiográficamente. Si Herrera publica a mediados del XVI un tratado haciendo esta exhortación, no podemos deducir, por ello, que el impacto de las Casas de las Arrepentidas fuera menor: teniendo en cuenta su expansión a lo largo de los siglos XV y XVI, habiendo al menos una en las principales ciudades de los reinos, esta institución puede entenderse como una importante prueba piloto de las medidas de encierro femenino.

Su generalización y regulación, eso sí, nos lleva a las galeras del XVII, entendidas como medidas nacionales de regulación civil. La migración jurisdiccional de las ciudades a la monarquía y de la regulación religiosa a la civil, inauguran una nueva fuente de saber y, sobre todo, una forma de hacer política difícil de comparar con la Edad Media. Con todo y con ello, sin ahondar en los mecanismos de control de la vida de las mujeres, no podríamos entender tampoco el modo en que se instaló el poder punitivo y el control social de la Modernidad. La búsqueda de una analogía a las Galeras masculinas, fruto estas últimas de una decisión protoestatal, indica la necesidad de regular la vida femenina y su (des)honestidad a una escala superior. No es consecuente ignorar la impronta de las Casas de las Arrepentidas en la historia del encierro ni en la capacidad de injerencia de las instituciones sobre la vida y sobre el orden de género si su función es muy cercana a la de las galeras.

Lo que con mucha frecuencia suele relegarse en la vida de Magdalena de San Jerónimo, como ya dijimos, es su experiencia como directora de la Casa de las Arrepentidas de Valladolid; muy distinta a la que Pérez de Herrera tuvo como médico de las Galeras masculinas. La constitución de estas casas, a veces conocidas con los apellidos que hemos señalado más arriba -María Magdalena, Egipcíaca, de la (A)probación, Recogidas, etc.-, y popularizadas con el epíteto de las arrepentidas -(re)penedides en el reino de Aragón-, se remonta al Trescientos y, sorprendentemente, tienen muchos más aspectos en común con las cárceles modernas que los calabozos medievales, las galeras masculinas o cualquier clase de pena aplicada con anterioridad al Seiscientos castellano o aragonés. En realidad, Zamudio fue continuista de una tradición con más de 200 años de antigüedad que, al amparo de una inquietud ya sembrada en otros países, y por Herrera cincuenta años atrás en Castilla, decidió dar otro paso y erigir unos centros de reclusión diseñados para las malas mujeres -delincuentes, hechiceras, alcahuetas, prostitutas, vagabundas, etc.- y sostenibles en el nuevo escenario político nacional. 
Magdalena de San Jerónimo dirigió y fundó la Casa de la Aprobación de Valladolid, una vieja institución en su funcionamiento pero nueva en su fundación. El hecho de que escribiera el Tratadillo, sin embargo, ha provocado que muchas historiadoras/es confundan esta Casa con la primera de las Galeras. San Jerónimo no dirigió ninguna galera (Torremocha 2014: 3740). El maremagnum de nombres de dichas casas, la difícil documentación y, a veces, confusa financiación en la época, e incluso la ambigua y desacompasada implantación de las galeras, a menudo mezclando a arrepentidas con delincuentes, ha hecho posible el desconcierto historiográfico. Probablemente, Magdalena de San Jerónimo, junto a Cristóbal Pérez Herrera, fueron los fundadores ideológicos de las galeras femeninas en España, pero no sus dirigentes ni sus antecedentes simbólicos.

Resulta que en estas casas del arrepentimiento se concentraban prostitutas, alcahuetas, vagabundas, terceras y delincuentes menores, todas ellas mujeres. Y, aunque el ingreso fuera relativamente voluntario, la intención de su internamiento era corregirlas y devolverlas a la buena policía de género. Sin embargo, la jurisdicción de estas casas y los procedimientos resultan tan irregulares, inconsistentes entre ciudades y aun esparcidos en documentaciones raras y escasas, que la historia parece haberlas ignorado por miedo, tal vez, a incurrir en imprecisiones historiográficas. Pero su existencia es innegable y probada, y la voluntad correctiva del encierro queda bien documentada gracias a la publicación de M. Amparo Vidal Gavídia: La casa de arrepentidas de Valencia (2001). Es solo una cuestión de tiempo y sensibilidad reparar su relevancia histórica.

La Casa Pía de la Aprobación dependía de la parroquia de San Nicolás y se ubicó allende la misma. La regía y administraba la Cofradía de Santa María Magdalena y cuya tutela recaía en el Duque de Lerma. Como en toda Casa de las Arrepentidas, las prostitutas, alcahuetas, terceras y delincuentes menores arrepentidas eran recogidas y adoctrinadas con la esperanza de convertirlas en monjas, a saber, recibir el hábito en San Felipe de la Penitencia ${ }^{13}$. En 1588, San Jerónimo compra de su bolsillo una serie de casas por el valor de 1.600 ducados, ya que la Casa destinada a la reclusión de prostitutas se le había quedado pequeña. No solo su fundadora se sintió generosa en este aspecto,

$\overline{13}$ Así queda recogido en una certificación realizada en 1597, a petición de Magdalena de San Jerónimo, del documento realizado en 1589 por Magdalena de Ulloa. AHN, Clero, Legajo 7.844 . 
tal y como queda recogido en la Escritura de la Concordia ${ }^{14}$ entre la señora D. Magdalena de San Jerónimo, el convento de San Pablo y la ciudad de Valladolid en 1605, importantes cantidades de dinero fueron donadas a su empresa por parte de la nobleza con el fin de seguir ampliando la casa.

Con todo, resulta bastante sencillo atribuir la causa de un cambio histórico a una persona sola: el personalismo historiográfico. A esta estética causal es muy aficionada la historia positivista, cuando nos remite a un descubrimiento que cambia el devenir de la técnica o la concepción del universo o la tierra. Por ejemplo, López Barahona (2013) comenta que:

A Magdalena de San Jerónimo le escandalizaba enormemente ver a tantas mujeres dedicadas al trato carnal o haciendo vida marital sin estar casadas, faltando a los sagrados preceptos del matrimonio, exigiendo condiciones para trabajar en una casa y mudándose de una a otra a su propio arbitrio; a tantas madres de criadas sospechosas de alcahuetería, y a tantas vagamundas, a las que achacaba fingir pobreza estando sanas para trabajar. Contra ellas pergeña una privación de libertad con unos suplementos punitivos crueles en forma de humillaciones como el rapado de pelo y los castigos corporales a fuerza de grillos, cadenas, esposas, cepos y "disciplinas de todas hechuras, de cordeles y hierros". (Barahona 2013).

De este modo, tenemos a una Magdalena de San Jerónimo que descubre o diseña un modo de castigar o rehabilitar relativamente novedoso o, por lo menos, puede leerse que su voluntad moral, sumada a su influencia en la Corte de la que habla con posterioridad, causaron la aparición de las Galeras femeninas ${ }^{15}$. Hecho que ignora no solo el impacto de las Casas de las Arrepentidas anteriores a San Jerónimo, sino también su propia experiencia al mando de la Casa Pía de la Probación en Valladolid.

Pensar que somos dueñas de nuestros actos está muy bien, sobre todo cuando una se lo aplica a sí misma, aquí y ahora, pero someter la historia a esa ficción no creemos que resulte muy interesante. Más que nada porque nos

${ }^{14}$ AHN, Patronato del convento de la Aprobación, t. 4, n. 5, libro 17295.

${ }^{15} \mathrm{El}$ texto va acompañado de muy interesantes reflexiones que recorren acertadamente los hitos del pensamiento penológico femenino, pero el anclaje histórico de las ideas sigue ligado a la figura del sujeto-que-descubre. 
perdemos todo el caldo de cultivo que, en torno a esa producción singular, florecía y avivaba ciertas perspectivas por encima de otras. Es como explicar un terremoto sin entender el movimiento tectónico, o calcular el desastre a partir de la escala Richter sin atender a las condiciones arquitectónicas y sociales del territorio afectado. La producción de Magdalena de San Jerónimo debe entenderse como la confluencia tectónica de símbolos, tradiciones, relaciones de género y políticas propias de una época; sus cartas y sus escritos deben situarse en la encrucijada de otros muchos textos, con la excepcionalidad de constituir, tal vez, la primera inflexión inteligible de un largo proceso: el de la historia de la reclusión como castigo. No es ni el principio ni el final de nada, es solo una parada obligada. Otras muchas habían escrito con anterioridad, también hubo experiencias anteriores de encierro que ya hemos mencionado y había incluso una noción de república que mudaba, y una de Estado que iba adquiriendo forma. Todo esto, tal vez, pudo convertir el tratadillo Razón y forma..., en uno de los fundamentos castellanos que la historia contempla para la cárcel moderna. Moderna, en todos los sentidos.

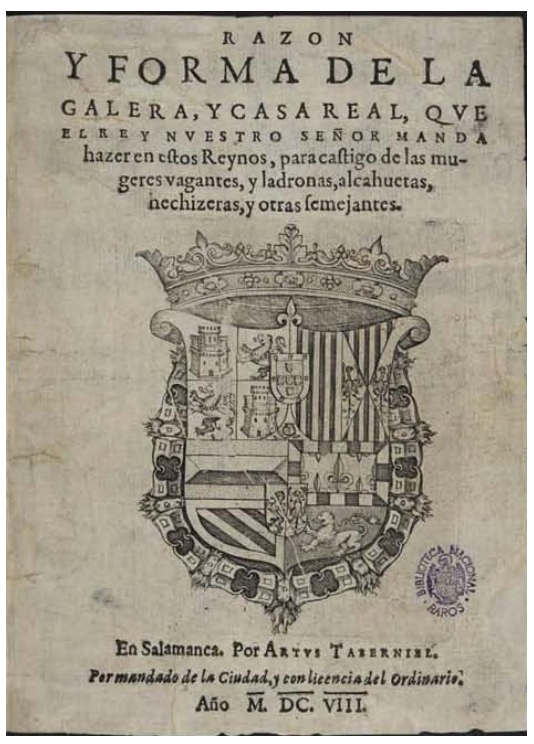

Fig. 3. Razón y Forma de la Galera. 


\section{Habiendo yo considerado y visto...}

Habiendo yo considerado y visto, con la experiencia de largos años [escribe Magdalena de San Jerónimo a Felipe III a principios de 1608] que gran parte (si no es la mayor) del daño y estrago que hay en las costumbres en estos reinos de España, nacía de la libertad, disolución y rotura de muchas mujeres, sentía (aunque gran pecadora) un gran dolor en mi alma, así de ver a nuestro gran Dios y Señor ofendido, como de ver este nobilísimo y cristianísimo reino estragado y perdido. (Barbeito 1991: 65).

Es, continúa, esta abrumadora tristeza que la mueve a escribir su tratadillo al rey, donde propone el establecimiento en toda España de cárceles para las mujeres como un remedio contra la "enfermedad y dolencia" que durante los últimos veinte años han asediado la república. Lo que quizás es lo más notable de la Razón y forma de la Galera son las condiciones específicas en las que se negocia la censura de las mujeres públicas. Estas -sostiene- "vagamundo y ociosas ... de mal vivir", son la fuente del gran daño o aflicción a la república:

que como muchas están dañadas, inficionan y pegan mil enfermedades asquerosas y contagiosas a los tristes hombres, que, sin reparar ni temer esto, se juntan con ellas; y éstos, juntándose con otras o con sus mujeres, si son casados, les pegan la misma lacra; y así, una de éstas contaminada basta para contaminar mucha gente. Y cuanta verdad sea esto lo muestran bien, por nuestros pecados, el Hospital de la Resurrección y los demás, donde se toman sudores y unciones, que para cada cama hay mil hombres. (Barbeito 1991: 72).

O sea, que el reproche a las prostitutas se funda, no por razones morales o religiosas, como sería de esperar, sino en el lenguaje de la infección y la circulación incontrolable. Este tráfico de órganos, enfermedad y de moneda, corolarios del trabajo sexual, también puede ser usado para describir el negocio del comercio y la recolección de reliquias en la España moderna, salvo por una diferencia notable: mientras que la amenaza-poder de la prostituta era que ella podía extender "enfermedades ${ }^{16}$ mil", el poder de la reliquia reside en su capacidad para curar a cualquiera de esos mil males. Esto, y el hecho de que

${ }^{16}$ Muy en particular la sífilis, más conocida en la España coetánea como el mal francés, el morbo gálico, el mal de Nápoles o, más comúnmente, bubas. 
tanto el contagio de la prostituta y la curación de la reliquia se pensaba que se realizaban por lo que podría ser visto como una especie de tropo del cuerpo -un contacto íntimo- que conduce a la intersección de dos cuerpos femeninos: el de la prostituta y el de -o parte de- la virgen mártir.

La tensión entre lo humano y lo deífico, entre lo profano y lo sagrado, entre el pecado y la curación, entre las razones de Estado y las leyes divinas (antes de que la Naturaleza fuera pensada en términos racionales), se instala en el cuerpo. El primer funcionalismo ${ }^{17}$ que dio forma a un cuerpo social, en analogía con el cuerpo individual, fue una premisa fundamental para comprender la lógica de la putrefacción y el remedio en los planos singulares y colectivos; entre el cuerpo singular de la mujer y la res pública, el vehículo circula en doble sentido, de abajo arriba el cáncer, y de arriba abajo la curación.

La enfermedad que transmite la mujer pública es, a la vez, simbólica y discursiva, vinculada a un cuerpo abierto o, mejor aún, a la apertura de un cuerpo. En marcada oposición al cuerpo cerrado de la virgen. Lo que la arrepentida significa, además, es el emblema viviente del sacramento de la penitencia -atacado por Lutero y, en consecuencia, institucionalizado como dogma en la decimocuarta reunión de Trento. Es la promesa de la pureza del alma, incluso o, especialmente, cuando la inocencia ya no está disponible para el cuerpo. Todavía más: la eficacia del sacramento, procedente del sacerdote, quien por su autoridad concede el perdón, se funda en la curación evangélica del paralítico, cuando el milagro de la sanación del cuerpo enfermo se presenta como prueba del poder de Cristo en el perdón de los pecados. Desplazamientos del bien y del mal que vuelven a indicarnos el sentido en el que viajan ambos, del cuerpo singular se extiende la enfermedad-pecado hacia el cuerpo social, y del cuerpo único, divino, ordenado y superior, llega la curación. La virgen se define por su cuerpo íntegro. La paradoja de esos cuerpos convertidos en reliquias es que, a mayor fragmentación -o sea des-integración-, mayor poder de curación, mayores milagros (Eire 1995). Su poder reside en la cualidad, no en la cantidad, puesto que su valor no está sujeto a la necesidad ni a la contingencia; es el cuerpo divino reificado por un cuerpo contingente glorificado, el nimbo que transita y cura y perdona y restituye desde arriba. La eficacia de la reliquia, a continuación, así como su valor de mercado, será completamente independiente al tamaño.

${ }^{17}$ Más conocido como el modelo fisiológico. 
Magdalena de San Jerónimo inició su actividad como dama de corte, trasladándose a Madrid para ejercer como dueña de cámara de la infanta Isabel Clara Eugenia, hija predilecta de Felipe II, a la que en 1598 el rey otorgó como dote los Países Bajos y el ducado de Borgoña en su inminente matrimonio con su primo hermano el archiduque Alberto de Austria, nieto de Carlos V. En la toma de posesión de la infanta como Soberana de los Países Bajos, fue acompañada hasta Flandes por Magdalena de San Jerónimo que consiguió, durante esta estancia, una autorización especial del papa Clemente VIII para recopilar un importante cargamento de reliquias procedentes de conventos e iglesias de Colonia y Tréveris. En 1604 Magdalena de San Jerónimo regresaba con su colección de reliquias desde Flandes a Valladolid, por entonces convertida en la capital de España. Su máxima preocupación era dotar de estabilidad económica a su fundación, la Casa Pía de la Aprobación, que había incrementado sus gastos, motivo por el que no había podido edificar una iglesia o capilla, ni una casa cómoda como residencia de las religiosas y las arrepentidas recogidas ${ }^{18}$.

Con la intención de aumentar el prestigio de su fundación vallisoletana y de conseguir donativos de los fieles, del Ayuntamiento y de la Corte para sus fines, Magdalena de San Jerónimo llevó a cabo un plan muy bien calculado: la entrega de los cuerpos completos de San Mauricio, mártir de la Legión Tebana, y San Pascual papa (Sangrador y Vítores 1851), uno a la ciudad de Valladolid y otro a la Casa Pía de la Aprobación, junto a un buen cúmulo de aquellas reliquias traídas de Flandes. Una de las reliquias tan veneradas, la que fuera destinada a una capilla dependiente de San Nicolás, donde realizaba sus cultos la Casa Pía de la Aprobación, fue acondicionada a petición de Magdalena de San Jerónimo en un relicario de plata repujada que estaba encerrado en un arca forrada de damasco y cerrada por tres llaves, acompañado por los relieves de los dos santos de su devoción: María Magdalena y San Jerónimo.

El otro cuerpo, perteneciente a San Mauricio, que sería entregado a la ciudad, fue depositado en un arca forrada de plata, con guarnición de terciopelo y detalles de bronce dorado, cuyo importe, dos mil reales de plata, fue costeado por el Ayuntamiento de Valladolid. Para recibir tan importante donación sacra, como era habitual por aquellos años, se prepararon grandes festejos, a los que asistieron los piadosos reyes Felipe III y Margarita de Austria.

\footnotetext{
$\overline{18}$ Archivo Municipal de Valladolid, Chancillería, Caja 39, Exp. 16, ff. 12r-12v.
} 


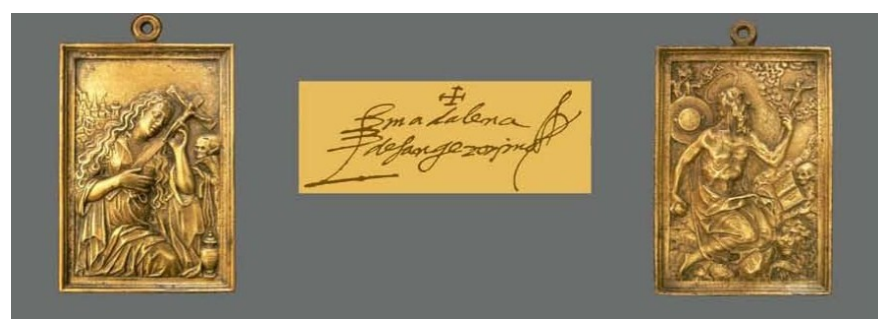

Fig. 4. Firma de Magdalena de San Jerónimo y relieves de María Magdalena y San Jerónimo.

En la tarde del 22 de septiembre de 1604, día de San Mauricio, tenido por santo patrono de la prestigiosa Orden del Toisón de Oro, salía una solemne procesión de la Catedral presidida por Juan Bautista Acevedo, Inquisidor General y obispo de Valladolid, vestido de pontifical, y, detrás, el Duque de Lerma, en su calidad de regidor de la ciudad, junto a los Príncipes de Saboya y representantes de los Consejos del Reino y del Ayuntamiento en pleno portando cirios, que se dirigieron hasta la Casa Pía de la Aprobación para recoger las reliquias. Al frente de la comitiva figuraba el estandarte de San Mauricio, de gran tamaño $(2,90 \times 1,70 \mathrm{~m})$ y confeccionado expresamente para tal acontecimiento, un guión realizado en damasco de seda de color carmesí, ribeteado de pasamanería dorada y pintado por sus dos caras por un anónimo pintor vallisoletano, en el anverso con la figura de San Mauricio y en el reverso con sus compañeros San Víctor y San Urso martirizados, también santos decapitados de la Legión Tebana, ambas escenas rodeadas de emblemas entre los que figuran los correspondientes a la ciudad de Valladolid, a la Cofradía de Santa María Magdalena, a la reina Margarita de Austria, al papa Clemente VIII y el anagrama de los jesuitas, defensores de la veneración a las reliquias. Este estandarte, sobrecogedor testimonio de toda esta historia, actualmente se conserva en el Museo de Valladolid (Wattenberg y Amigo 2012: 91-95).

Una vez hecha la entrega, el cortejo, presidido por el Estandarte de San Mauricio, con atabales, trompetas y grupos de danzantes, regresó hasta la Catedral:

Por la tarde hubo una una solemnísima procesión, en que se llevó el cuerpo del glorioso mártir tebeo, que traxo de Flandes Madalena de San Gerónimo, y le dió a la ciudad; fuele acompañando otro santo cuerpo. Hizo el oficio el obispo de Valladolid, inquisidor general, 


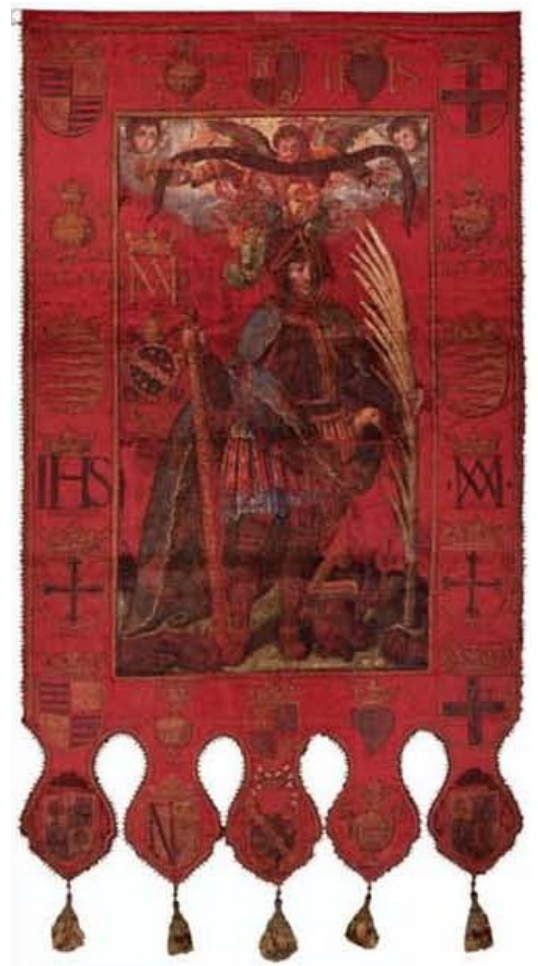

Fig. 5. Estandarte de San Mauricio.

vestido de pontifical; yba la Ciudad y el duque de Lerma, como regidor della, detrás, con cirios blancos. En la Plaça de Palacio, debajo de las ventanas donde sus magestades estaban, se hizo un rico altar con tres gradas, lleno de reliquias del oratorio de la reyna, nuestra señora, con una gran valla, dentro de la qual estaban dos bufetes cubiertos con paños de brocado, sobre los quales se pusieron las urnas de los dos santos, y allí cantaron los cantores de la capilla real dos motetes. Tocaronse las chirimías y otros instrumentos y de allí prosiguió la procesión. (Diego de Guzmán 1617).

Después se leyeron las poesías de un concurso en alabanza de los "cuerpos santos tebanos" y se quemaron, en distintas plazas, fuegos artificiales organizados por el Ayuntamiento. 
Dos semanas más tarde de tan notable y concurrido acontecimiento, Magdalena de San Jerónimo solicitaba al Ayuntamiento que se hiciera cargo de la Casa Pía de la Aprobación, hecho que se consumó el 13 de marzo de 1605, compartiendo el patronato con el prior del convento de San Pablo. Conseguidos sus objetivos, Magdalena de San Jerónimo regresó a Flandes, comenzando a urdir la creación de cárceles correccionales para mujeres públicas y delincuentes. En la correspondencia girada con Luisa de Carvajal, las dos amigas hablan varias veces de reliquias:

A doña Ana de Peñalosa di sus recaudos de vuestra merced y dije lo que me mandó de la reliquia; creo que me dijo que escribía a vuestra merced (Abad 1965: 111 [29.01.1601]).

En acabando estos embarazos, espero que abrirá Nuestro Señor camino en lo que querrá de mí, y me dará cómo lo pueda ejecutar valerosamente. $\mathrm{Y}$ podrá ser que vamos a participar en los andrajos que dice vuestra merced han de hacer un día a mi Madalena, por el amor de Nuestro Señor y que con su compañía me quepa a mí tan buena suerte (Abad 1965: 118 [11.01.1602]).

Deseo saber qué eran los andrajos que vuestra merced heredó de esa santa mujer: porque dice tener un cofre lleno, y para andrajos parécenme muchos (Abad 1965: 124 [24.08.1602]).

Y lo primero, digo que sea muy enhorabuena venido el tesoro de las reliquias, que lo es sobre los tesoros todos de la tierra sin alguna comparación (Abad 1965: 127 [25.01.1603]).

En lo que vuestra merced manda, del pie o mano, tendré cuidado; aunque es una de las cosas más dificultosas que hay aquí: ese pedacico me ha dado en la cárcel un sacerdote, muy mi conocido, por muy cierto; y todos me decían que este sacerdote era el que mejor lo podía dar, y así lo ha hecho. No lo envío guarnecido, porque ya sabe vuestra merced las estrechuras de mis pobrezas. (Abad 1965: 183 [24.07.1606]).

Además de los cuerpos de San Mauricio y San Pascual, estaban los de las once mil vírgenes que acompañaron a Santa Úrsula al martirio, así como las cabezas de al menos veinte de ellas. La hagiografía de Santa Úrsula, que se remonta a la ciudad de Colonia del siglo $\mathrm{X}$, da cuenta de la leyenda: $\mathrm{A}$ Úrsula, hija de un rey cristiano en Gran Bretaña, se le pidió en matrimonio 
por el hijo de un rey pagano. Ella, ya que deseaba permanecer soltera, se retrasó tres años, los cuales pasó a bordo de un barco, navegando por los mares; tenía diez nobles que la acompañaban, cada uno de ellos, y Úrsula, tenía mil compañeras. Al final del período de gracia, vientos contrarios los condujeron la desembocadura del Rin, el barco navegó hasta Colonia y luego a Basilea, donde desembarcó. Luego se acercó y cruzó los Alpes para visitar las tumbas de los apóstoles en Roma. Volvieron por el mismo camino hasta Colonia, donde fueron atacados y masacrados por los hunos paganos, dado que la cristiana Úrsula se había negado a casarse con su jefe. Los bárbaros fueron dispersados por ángeles, los ciudadanos enterraron a los mártires y se construyó una iglesia en su honor (Butler 1994: 130).

En las constituciones del Patronato que San Jerónimo funda en 1605 en beneficio de la Casa de las Arrepentidas de Valladolid se dice:

Y su Majestad, movido del santo celo con que quiere la conservación de obras tan pías y públicas y en que nuestro Señor es tan servido, a instancia de la dicha Madre Magdalena de San Jerónimo y de su pedimiento, ha hecho y hace la merced a la dicha casa y obra pia de que haya y cobre en la dicha casa de las comedias de esta dicha ciudad, un cuarto de cada persona que entre a oírlas. Y la dicha Madre Magdalena de San Jerónimo con su bien cuidado y diligencia y trabajos que ha sufrido, ha juntado y recogido los bienes y reliquias de que adelante se hará mención, todo lo cual quiere y tiene por bien de aplicar y aplica a dicha casa y obra pía; y de ello hará donación. Y habiendo considerado su Majestad que en la dicha obra consiste muy particularmente el bien público de esta ciudad [...] ha sido servido de ordenar y mandar que el Ayuntamiento, Justicia y Regimiento de esta dicha ciudad, se encargue de la dicha casa y obra pía... (Barbeito 1991: 44). ${ }^{19}$.

Hay una serie de aspectos de este pasaje que merecen ser comentados: el uso de la palabra conservación, para empezar. No solo es un ejemplo de la transferencia de una retórica médica sobre una esfera política -un movimiento coherente con el modelo fisiológico de la república como cuerpo-, sino que, si creemos a Maravall (2002: 126-147), podría ser aportada como prueba de una cultura conservadora o, por lo menos, de una cultura de conservación. Como

${ }^{19}$ Nuestras elipsis y cursivas. 
observó astutamente Elliott, conservación es "una palabra que serpentea a través de la literatura política y los registros de debate conciliar en los reinados de Felipe III y Felipe IV" (Elliott 1989: 250). No sorprende, entonces, encontrar su cita en el tratado penal de Magdalena de San Jerónimo.

O los diversos usos a los que se somete la palabra pública: Obras Públicas - como la Casa Pía-, que contribuyen al Bien Público de la ciudad y, en términos más generales, de la nación - la res publica-, junto a la Casa Pública -la casa de putas-, el fantasma en la máquina de la casa Magdalena: había más de 800 burdeles solo en Madrid cuando Felipe IV llegó al trono. Hay un cambio notable aquí. La distancia o tensión entre estos dos usos de lo público había sido anteriormente solo uno; los burdeles habían sido legales en España, al menos desde la Edad Media, precisamente porque eran considerados beneficiosos para el público, no solo porque contenían física, regular y legalmente las amenazas representadas por las mujeres públicas a la sociedad, sino también como una especie de mal necesario, tolerado para evitar delitos más graves contra Dios o la Naturaleza - el mal nefando, la homosexualidad, por ejemplo (Cuadrada 2015). A lo largo de los reinados de los tres Felipes, esa distancia se hace cada vez mayor, a medida que los moralistas sostienen que las casas públicas son incompatibles con el Bien Público, precisamente por ser un foco de contagio, independientemente de las ventajas prácticas que conllevaban, acusando de herejía la opinión generalizada según la cual, si era pagada, la fornicación no era pecado (Tomás y Valiente et al. 1990: 57-89).

Es interesante examinar, también, los mecanismos específicos de la operación que se describe en las Constituciones y lo que inciden sobre la política de la representación visual de ahora, al menos, tres tipos diferentes de organismos públicos. Magdalena de San Jerónimo se compromete a renunciar a sus reliquias a favor de la ciudad, prostituyendo, en cierto sentido, los cuerpos de sus vírgenes para las almas de sus magdalenas. La restitución divina del cuerpo perdido, del cuerpo de la prostituta que viaja entre otros cuerpos y se apodera de ellos. Del demonio que opera en las almas más débiles y las hace temibles y poderosas. El lenguaje del alma se invoca en toda la Razón y forma de la Galera. Pero vale la pena señalar aquí que no es una Casa Pública a partir de la cual las ganancias beneficiarán a Valladolid, como fue el caso general: el argumento más fuerte a favor de mantener los burdeles abiertos, a principios del siglo XVII era, precisamente, el económico, dado que proporcionaban ingresos considerables para la caridad. En su lugar, el 
teatro público, lo que sugiere una vuelta de tuerca barroca: la comedia como la puta impenitente, cuyos beneficios favorecerán a las arrepentidas.

San Jerónimo, a continuación, lleva a cabo la conexión de estos lugares públicos: el prostíbulo, el teatro y la Casa Pía. Las casas de comedia estaban igualmente bajo el ataque de los mismos moralistas y teólogos que denostaban los burdeles y, por motivos casi idénticos; es decir, como el caldo de cultivo de lascivia y pecado. En 1600, el Dictamen de Fray Agustín Dávila, electo de Santo Domingo y otros teólogos de Madrid sobre la permisión de comedias, recomienda severamente: "Que no representasen mujeres en ninguna manera, porque en actos tan públicos provoca notablemente una mujer desenvuelta, en quien todos tienen puestos los ojos" (Cotarelo y Mori 1904: 208). Era, de hecho, la presencia del cuerpo de la actriz en el escenario lo que daba cuenta de la tremenda popularidad del teatro en la España moderna (McKendrick 1989: 203).

Partes de cuerpo intercambiables: de la virgen, de la prostituta, y de la actriz. El funcionamiento es más o menos así: Magdalena donará al público las partes del cuerpo de sus vírgenes - partes íntimas hechas públicas, no solo por su exhumación (necesaria para su distribución como reliquias), sino sobre todo por su participación en varias economías de deseo, de cambio y vener(e)ación pública. A cambio de este legado, el rey decreta que una parte del impuesto sobre el teatro -un impuesto como gravamen sobre su exhibición pública, dentro y fuera del escenario- circulará hasta la casa de las Magdalenas. Ese dinero favorecerá la contención y la reforma de las mujeres, cuyo crimen había sido el comercio y la exhibición pública de sus cuerpos y, en particular, de las partes privadas de sus cuerpos, pero cuya condición de arrepentidas hace a sus almas y cuerpos, una vez convertidos, en privados, clausurados.

Esta tensión entre lo público y lo privado también se puede analizar en los vericuetos entre los distintos escenarios públicos. Es el traslado de las reliquias más allá de las fronteras nacionales o imperiales, entendido ahora tanto como un negocio de importación y exportación potencialmente lucrativo y como divina Misión: salvarlas de la destrucción a manos de los iconoclastas protestantes; la contención de la reliquia dentro de las paredes, por así decirlo, del relicario; la procesión de prostitutas convertidas desde la casa pública a la casa de las Magdalenas, una procesión que tenía toda la pinta de un desfile. En una carta del 10 de mayo de 1623, Andrés de Almansa y Mendoza la describe: 
Fueron en procesión cincuenta y dos mugeres vestidas con sacos de sayal, descalças, cubiertas con velos blancos de dos en dos, y con velas blancas en las manos acompañadas del Vicario general de Madrid, y de toda su Clerecía, Cruzes y estandartes; y del Corregidor y Regidores en forma de Villa, con sus porteros y maceros; estando en la puerta del Sol el Conde de Olivares, y otros Señores que llevaron al Príncipe de Gales a ver pasar dicha procesión. (Simón Díaz 1982: 231).

La reclusión de las prostitutas en la casa de las Magdalenas durante la Cuaresma, en el aniversario de la conversión de María Magdalena, y en los nueve días de fiesta de la Virgen; el encarcelamiento de la prostituta vagante en la galera; la peregrinación de órganos y organismos - a menudo enfermos- a la iglesia a adorar el cuerpo de la virgen y mártir, al teatro para contemplar el cuerpo de la actriz, o al prostíbulo para disfrutar del cuerpo de la prostituta; el movimiento del cuerpo de la actriz de un teatro a otro, o de una ciudad a otra, movimiento errático asociado al de la puta-vagamunda, o de fuera del escenario al escenario; de la calle al hostal, y así cualesquiera otros espacios pueden añadirse: desde los Hospitales de la Resurrección, de hacinamiento de pacientes sifilíticos, al Escorial mismo.

Tal vez la paradoja más notable, sin embargo, tiene que ver con el desmembramiento o el olvido del subtexto fundamental que une a todas estas mujeres: el mito de la Magdalena. Existe un número importante de estudios sobre la Magdalena (Haskins 1993; Duperray, Duby y Pietri 1988; Davis 1993; Mosco 1986; Malvern 1975; Tamarit 2010). Se unen en la Magdalena narrativas de prostituta y virgen, de santa y pecadora -beata peccatrix - ambos guiones sobre su cuerpo, un cuerpo destinado a convertirse en una de las más valiosas reliquias de la Iglesia Católica Romana. Más importante, quizás, en términos de su papel en la religiosidad moderna, la penitencia de Magdalena constituía un flagrante acto de auto-(re)modelación, al igual que la repetición virtual de la práctica por la que decenas de miles de arrepentidas, en el aniversario de su patrona de conversión, se retractaban en su nombre y, literalmente, muchas de ellas adoptaban el nombre de Magdalena como marca de su contrición ${ }^{20}$. Lo que tenemos, entonces, ya no son actrices actuando en unas obras de teatro u otras, indiscriminadamente, de Magdalena o de prostituta, sino prostitutas que ejercen de buena fe el papel de la Magdalena, ella misma prostituta, en el juego de la Contrarreforma de la Iglesia, acto II, el de la santa.

${ }^{20}$ Lo que podría dar lugar a especulaciones interesantes sobre la adopción del nombre por parte de Beatriz de Zamudio, como hemos insinuado más arriba. 


\section{Conclusiones}

Pero hay, por supuesto, un cuerpo más que está implicado en todo esto. Nos gustaría concluir planteando algunas preguntas acerca de cómo las partes de las prostitutas y las reliquias de Magdalena de San Jerónimo podían ser útiles a los organismos públicos y privados, o al que ha estado acechando aquí todo el tiempo: el cuerpo del imperio español a finales del siglo XVI y principios del XVII. La analogía generalizada entre el Estado y el cuerpo humano en las primeras teorías políticas españolas modernas hace que el lado de la ecuación donde se halla la prostituta sea bastante predecible, sobre todo si se recuerdan las amenazas al orden social de la prostituta errante.

En un fascinante estudio de la relación entre las mujeres no cerradas y el orden social de la primera Italia moderna (Shemek 1998), se comprueba que el peligro más inmediato que ellas encarnaban era el de las enfermedades venéreas. Teniendo en cuenta, por una parte, que la sífilis estaba no solo generalizada y se consideraba letal, así como también la fuente de muchas ansiedades culturales; y, por la otra, que el proceso de política nacional y disminución fue descrito "en términos de enfermedad debilitante" (Elliott 1989: 249), no es, esperamos, ir demasiado lejos al sugerir que la línea de separación de estas dos enfermedades puede haber sido muy frágil. Ello abre la posibilidad de lectura de un cuerpo de España fantaseado como una mujer pública o, más sorprendentemente aún, como una puta sifilítica. Las etiologías se solapan con la decadencia nacional, y el morbo gálico se invierte en este tipo de demanda, señalando formas en que la sífilis puede haber funcionado como una especie de palanca de cambios para diferentes afecciones del cuerpo político, y plantea dudas sobre la medida en que tal fantasía - de un estado corporativo sifilítico, por ejemplo- podría haber servido como una crítica no solo del tamaño, la forma y el estado del cuerpo del imperio, sino, aún más problemática, de la propia empresa imperial.

¿Cuáles fueron, entonces, estas etiologías? Prevalecieron dos teorías. La primera fue estrictamente providencialista: la sífilis imaginada como el resultado de un acto del juicio divino, castigo de los pecados. Ya en 1498, Francisco López de Villalobos, uno de los primeros médicos -no solo en España, sino en toda Europa- en documentar la nueva viruela, la define desde la perspectiva teológica: "Dirán los teólogos que este mal vino por nuestros pecados [...] o Gran Providencia o juicio divino"21 (Granjel 1980: 210). Lenguaje totalmente

${ }^{21}$ Nuestra elipsis. 
en consonancia con el discurso providencialista empleado por los teóricos y los arbitristas para dar cuenta de las aflicciones del estado corporativo, que no debe sorprendernos tanto, dado que pone en cuestión qué pecados particulares de este organismo nacional o imperial estaban siendo castigados.

Un buen ejemplo de la analogía generalizada entre el Estado y el cuerpo humano en el Seiscientos es el Arte real para el buen govierno de los Reyes, y Príncipes, y de sus vassallos de Jerónimo de Ceballos (1623). Escribe sobre la:

similitud entre el gobierno de un sistema de gobierno y el cuerpo humano, que también sufre de exceso o por causas naturales; y la misma cosa que sucede a la república, que entra en declinación, ya sea por mal gobierno [...] o por causa de desastres naturales [...] $\mathrm{Su}$ Majestad es el médico de esta república y sus vasallos son los enfermos $^{22}$. (Ceballos 1623).

Otro es la Conservación de monarquías de Pedro Fernández de Navarrete (1626), que sostiene que "la enfermedad [que tiene abatido al estado español] es extremadamente grave". En su Restauración Politica de España, Sancho de Moncada (1619) expone:

España ha cambiado más en los últimos cuatro o cinco años que durante los últimos cuarenta o cincuenta años, como un viejo pero sano hombre, que de repente en el espacio de unos pocos días se pone bajo la enfermedad que lo llevará a la tumba. (de Moncada 1619).

Mateo de Lisón y Biedma presenta un argumento similar en sus Discursos y Apuntamientos (1622): "Este hombre enfermo es la monarquía de Su Majestad" (Elliott 1989: 248-250).

La teoría imperante del segundo origen de la sífilis ofrece otra posible respuesta. El mal francés y el mal de Nápoles eran nombres inapropiados, ya que la enfermedad era un fenómeno americano que viajó hacia el Este desde el Nuevo Mundo. Es precisamente en estos términos que Sebastián de Covarrubias define la enfermedad en su Suplemento al Tesoro de la lengua (1613):

${ }^{22}$ Nuestras elipsis. 
BUBAS. (Añade). Esta enfermedad cundió mucho en la guerra de Nápoles quando Carlos octavo rey de Francia se apodero de él, excluyendo a don Fernando. Pegábase principalmente por la comunicaçión deshonesta. Los Italianos le llamaron entonçes mal Francés, los Franceses mal de Nápoles, los Africanos mal de España. La verdad es que vino del nuevo mundo donde este mal de las bubas es muy ordinario, y como se ubiese desde allí derramado por Europa como lo juzgan los más avisados, por este tiempo los soldados Españoles le llevaron a Italia y a Nápoles. Mariana lib. 26, capite décimo. Zorita quinta parte, lib. 5, cap. 62. (Covarrubias 1613: 106).

¿Pero dónde están las reliquias en este vasto, enfermo, e incluso promiscuo cuerpo Imperial? Una respuesta llega al considerar el proyecto de recogida de reliquias -de Felipe II, en particular, pero también de Felipe III- como algo homólogo a lo imperial. Bulas papales, como la que se concedió a Felipe II en 1567 por Pío V (Bouza Álvarez 1990: 35); la concesión de permiso a los reyes españoles a extraditar cuerpos de santos desde donde fuera para descansar en el Escorial puede verse, entonces, como una extensión de la bula papal que poco más de un siglo antes habían gozado sus bisabuelos, Fernando e Isabel, con los derechos imperiales inalienables en América. Podría argumentarse, aún, que España rescataba preciosas reliquias en el Viejo Mundo tan celosamente como extraía los metales preciosos en el Nuevo. Ambos proyectos se enmarcan y justifican religiosamente y eso no es de ninguna manera una coincidencia.

Otra manera de responder a la cuestión de la relación entre las partes del cuerpo de la reliquia y las del Imperio es considerar el papel de la retórica en general y la de un tropo en particular. Proponemos que la sinécdoque -el tropo de la parte por el todo, uno que los retóricos de la temprana Modernidad consideran una instancia de la metonimia- es el tropo de la reliquia. El poder de la reliquia es, como hemos visto, independiente de su tamaño, porque cualquier fragmento, independientemente de lo minúsculo y mínimo que sea, sustituye eficazmente el conjunto. El tamaño, en lo que se refiere a las reliquias, no importa. Pero la sinécdoque también ocupa un lugar destacado en los argumentos a favor y en contra de las restricciones a la autoridad imperial. Si el modelo del Sacro Imperio Romano constituía la mejor defensa del expansionismo territorial, las nuevas geografías y la nuevas cartografías, después de 1492, desafiaron la validez de ese modelo. 
El descubrimiento de que existía todo un continente del cual los antiguos habían sido totalmente ignorantes, excluía la posibilidad de que cualquier emperador pretérito hubiera podido ser un gobernador del mundo (Pagden 1995: 38-9). A partir de ahí, no fue difícil dudar de cualquier emperador coetáneo que proclamara un gobierno mundial apoyándose en el modelo romano. Domingo de Soto en De iustitia (1556), limita el dominio imperial del antiguo imperio romano porque ningún césar podría ser literalmente "Señor de Todo Mundo", ya que -y esto es especialmente interesante para lo que nos ocupala parte que gobernaba era muy pequeña en relación con el conjunto total. Aquí el tamaño sí que importa. Por supuesto, la mejor estrategia para la lucha contra este tipo de reclamos era apelar, y de manera bastante explícita, a los poderes de sustitución de la sinécdoque. Francisco Ugarte de Hermosa y Salcedo hace exactamente esto en su Origen de los gobiernos divinos y humanos y forma de su exercicio en lo temporal (1655). Citando a san Agustín casi palabra por palabra, argumenta Ugarte que la expresión "Todo el mundo" era lo que iba a ser entendida como una sinécdoque: el todo -todo el mundo que los antiguos sabían- convirtiéndose en el aquí parte de un nuevo conjunto y que, como tal, podría extenderse para acomodar la forma hinchada del globo. Pagden dice:

Una de las estrategias para la recuperación de la antigua imagen del imperio [...] era argumentar, como san Agustín había hecho, que "todo el mundo" de hecho era solo una sinécdoque, y podría por tanto, ampliarse hasta cubrir todas las tierras recién descubiertas y, por si acaso, cualquier tierra que podría descubrirse en el futuro (Pagden 1995: 39$)^{23}$.

Como el tropo de la reliquia también se pone al servicio del imperio, la sinécdoque podría ser vista como el tropo retórico que, de alguna manera, conecta reliquias y el imperio. Existe también otra forma -quizá la más importante- para imaginar esa relación. Tiene que ver con el grado en que las partes del imperio pueden ensamblarse para formar un todo orgánico, un organismo nacional. Y esto, precisamente, es lo que en términos de Vance significa la estética de la reliquia: el paso de la aprehensión de un fragmento marcado por la violencia del desmembramiento, la calcinación o el desollado de los cuerpos humanos, a la visión de un resplandeciente, de un todo resucitado (Vance 1988: 172). En su estudio de la relación entre reliquias, iconos e

${ }^{23}$ Nuestra elipsis. 
imperio carolingio, argumenta que existe una clara homología en la idea del imperio carolingio como una totalidad. Es decir, las afirmaciones ideológicas de los carolingios como un discurso, donde la unidad, verdad, santidad y poder eran categorías estéticas (Vance 1988: 172).

A principios de la España moderna, esta estética es quizás mejor entendida como una teleología nacional que está, por supuesto, ya en crisis severa en el momento en que Magdalena de San Jerónimo escribe: la promesa que muchos pueden ser uno, que las multiformes partes privadas pueden, al final, juntarse formando un cuerpo público.

Ya como epílogo, queremos relatar una anécdota que, en cierto sentido, une los diversos organismos públicos y las piezas privadas. Todavía hemos de referirnos a otra parte del cuerpo: los mechones de pelo de María Magdalena que la catedral de Oviedo afirma que posee y que aparecen en primer lugar entre sus reliquias más valiosas, únicos cabellos de la Magdalena en toda España. Podemos imaginar que, en su frenesí de recogida de reliquias, Felipe II habría intentado desesperadamente conseguirse la cabellera de valor incalculable, para poder guardarla en su colección de El Escorial, en la que había acumulado 7.420 reliquias en el momento de su muerte, en 1598. Es dudoso que su aventura acabara con éxito; Oviedo no renunció a ella. Pero aún más interesante, quizás, que la obsesión de Felipe, fue la justificación del rey para la translatio de los hilos preciosos -la misma razón, que dio cuando solicitó a la ciudad de Santiago de Compostela el cuerpo del santo patrón de España. Felipe defendió no solo la superioridad de El Escorial como archivo hagiográfico (Estal 1970), sino los incontables beneficios que para el cuerpo del imperio y para España entera derivarían al tener al rey y a su patrón en proximidad metonímica (Eire 1995: 266-267).

Sin embargo, y acabando un tanto perversamente, la apreciada reliquia de la beata peccatrix que tanto anhelaba el monarca, no era más auténtica que las decenas de prepucios de Cristo o los miles de muelas de san Cristóbal dispersas y reverenciadas en toda Europa, de las que hicieron mofa Erasmo, Calvino y Alonso de Valdés, entre otros. En su Diálogo de las cosas ocurridas en Roma, Valdés escribe:

Pues desta manera hallaréis infinitas reliquias por el mundo y se perdería muy poco en que no las oviesse. Plugiesse a Dios que en ello se pusiesse remedio. El prepucio de Nuestro Señor yo lo he visto en Roma y en Burgos, y también en Nuestra Señora de Anversia, y la 
cabeça de Sanct Johan Baptista en Roma y en Amians de Francia. Pues apóstoles, si los quisiéssemos contar, aunque no fueron sino doce y el uno no se halla y el otro está en las Indias, más hallaramos de veinte y quatro en diversos lugares del mundo [...] Dientes que mudava Nuestro Señor quando era niño passan de quinientos los que se encuentran solamente en Francia. Pues leche de Nuestra Señora, pelos de la Madalena, muelas de Sant Cristóbal, no tienen cuento ... (Valdés 1969: 121-5).

Estos pelos de Magdalena de Felipe tan codiciados - para sanar su propio cuerpo, para curar a la nación- era menos probable que fueran el cabello que secó los pies de Jesús que la melena rasurada de una de las pupilas de la galera de Magdalena de San Jerónimo, un mechón perdido de una enferma de bubas, o incluso un flequillo de la peluca de una actriz sin vergüenza, haciendo tanto de Magdalena como de puta. O, para darle el último giro a la tuerca proverbial, sin pelos en la lengua, sino en la pluma de una Pícara Justina, o de una magdalena, tal vez, de cualquier otro nombre.

\section{Listado de Imágenes}

Imagen 1. Juan de Courbes: Retrato de Luisa de Carvajal y de Mendoza (1623). Estampa a buril incorporado a la Vida y virtudes de la venerable virgen Doña Luisa de Carvajal de Luis Muñoz. Inscripción: "La Venerable Virgen D. LVISA de CARVAJAL y MENDOZA Ilustre / en Santidad y Nobleza: rara en todas las virtudes: vnica en el zelo de la / Religión Catolica: murió en Inglaterra a 2 de Enero de 1614 años, a los 47. / de su edad. Venérase su cuerpo en el relicario del Real Convento de la Encarnación". Madrid, Biblioteca Nacional de España. Disponible en: https://es.wikipedia.org/wiki/Luisa_Carvajal_y_Mendoza\#/media/File: Courbes-Retrato_de_Luisa_Carvajal_y_Mendoza_1.jpg [Consulta 29.12.16].

Imagen 2. Casa Pía de la Aprobación (Valladolid). Información parcial del plano de Ventura Seco (1738). Señalado en color el edificio ya desaparecido de la Casa Pía de la Aprobación. Disponible en:

http://domuspucelae.blogspot.com.es/2012/11/historias-de-valladolidmagdalena-de_9.html [Consulta 29.12.16].

Imagen 3. Edición de la obra de Magdalena de San Jerónimo, Razón y Forma de la Galera ..., Salamanca 1608. Biblioteca Nacional, Madrid. Disponible 
en: http://domuspucelae.blogspot.com.es/2012/11/historias-de-valladolidmagdalena-de_9.html [Consulta 29.12.16].

Imagen 4. Firma de Magdalena de San Jerónimo y relieves de María Magdalena y San Jerónimo. Disponible en: https://diogeneschilds.wordpress.com// $? \mathrm{~s}=\mathrm{raz} \% \mathrm{C} 3 \% \mathrm{~B} 3 \mathrm{n}+\mathrm{y}+$ forma $+\mathrm{de}+\mathrm{la}+$ galera\&search $=\operatorname{Ir}$ [Consulta 29.12.16].

Imagen 5. El Estandarte de San Mauricio se conserva en el Museo de Valladolid (Palacio de Fabio Nelli) y fue terminado de restaurar el año 2011 por el Centro de Conservación y Restauración de Bienes Culturales de Castilla y León, dependiente de la Junta de Castilla y León y situado en la localidad de Simancas (Valladolid). Está confeccionado en seda natural teñida y tiene forma rectangular, en sentido vertical, compuesto por tres paños cosidos y un dobladillo para alojar una vara horizontal, con un remate en la parte inferior de cinco lóbulos de los que penden borlas. Las pinturas están aplicadas al óleo, sin base de preparación, y se acompaña de ribetes de hilos dorados. Disponible en: http://domuspucelae.blogspot.com.es/2012/11/historiasde-valladolid-magdalena-de_9.html [Consulta 29.12.16].

\section{Fuentes}

- Archivo Histórico Nacional.

- Archivo Municipal de Valladolid.

- Abad, Camilo María (1965). Doña Luisa de Carvajal y Mendoza, epistolario y poesías. Madrid: Biblioteca de Autores Españoles, tomo CLXXIX.

- Cotarelo y Mori, Emilio (ed.) (1904). Bibliografía de las controversias sobre la licitud del teatro en España. Contiene la noticia, extracto o copia de los escritos, así impresos como inédito, en pro y en contra de las representaciones. Madrid: Revista de Archivos, Bibliotecas y Museos.

- La vida de Santa María Egipcíaca de Rutebeuf (2006). Introducción, edición, traducción y notas por Miguel Ángel García Peinado y Ricardo Redoli Morales. Cuenca: Universidad de Córdoba-Universidad Castilla La Mancha.

- Pérez de Herrera, Cristóbal (1598). Discurso de amparo de los legítimos pobres y reducción de los fingidos. Madrid: por Luis Sánchez.

- Sigüenza, José de (1853). Vida de S. Gerónimo, doctor máximo de la Iglesia, sacada de sus obras ... Madrid: Imprenta de La Esperanza. 
- Tesoro de la lengua castellana o española (1611) de Sebastián de Covarrubias. Disponible en:

- Valdés, Alonso de (1969) [1532]. Diálogo de las cosas ocurridas en Roma. Madrid: Espasa Calpe.

- Vives, Juan Luís (1525). Tratado del socorro de los pobres.

\section{Agradecimientos}

GRAMP.-UB 2014SGR1252. Este artículo se inserta en los proyectos EUIN201562506 y HAR2015-65285-R. https://urv.academia.edu/CoralCuadrada

\section{Bibliografía}

1. Abad, C.M. (1966). Una misionera española en la Inglaterra del siglo XVII: doña Luisa de Carvajal y Mendoza. Santander: Universidad Pontificia de Comillas.

2. Almeda Samaranch, E. (2002). Corregir y castigar: el ayer y hoy de las cárceles de mujeres. Barcelona: Bellaterra.

3. Amussen, S.D. (1985). Féminin/masculin: le genre dans l'Angleterre de l'époque Moderne. Annales. Économies, Sociétés, Civilisations, 40(2): 269-287.

4. Barbeito, I. (1991). Cárceles y mujeres en el siglo XVII. Biblioteca de escritoras 21. Madrid: Castalia \& Instituto de la Mujer.

5. Butler, A. (1994). One Hundred Saints: Their Lives and Likenesses. Drawn from Butler's 'Lives of the Saints' and Great Works of Western Art. Boston: Bulfinch Press/Little, Brown and Company.

6. Canesi Acevedo, M. (1996). Historia de Valladolid (1750), tomo III. Valladolid: Grupo Pinciano, edición facsímil.

7. Cuadrada, C. (2015) [2016] Historias de silencios: las palabras de las putas (siglos XV-XVI). Clio \& Crimen, 12: 323-364.

8. Davis, E. B. (1993). "Woman, why weepest thou?": revisioning the Golden Age Magdalen. Hispania, 76(1): 38-48.

9. Duperray, E., Duby, G. \& Pietri, Ch. (eds.) (1988). Marie Madeleine dans la mystique, les arts et les lettres. Avignon: Beauchesne.

10. Eire, C.M.N. (1986). War Against the Idols: The Reformation of Worship from Erasmus to Calvin. Cambridge: Cambridge University Press.

11. Eire, C.M.N. (1995). From Madrid to Purgatory: The Art and Craft of Dying in Sixteenth-Century Spain. Cambridge: Cambridge University Press.

12. Elliott, J.H. (1989). Self-perception and decline in early seventeenth-century Spain. In Spain and Its World 1500-1700. Selected Essays (pp. 241-261). New Haven: Yale University Press. 
13. Estal, J.M. del (1970). Felipe II y su archivo hagiográfico de El Escorial. Hispania Sacra, 23: 193-335.

14. Federici, S. (2004). Calibán y la bruja. Mujeres, cuerpo y acumulación originaria, Madrid: Traficantes de sueños. Recuperado el 3/11/2016 de https://www.traficantes.net/sites/default/files/pdfs/Caliban\%20y\%20la\%20 bruja-TdS.pdf

15. Granjel, L.J. (1980). Medicina española renacentista. Salamanca: Ediciones Universidad de Salamanca.

16. Haskins, S. (1993). Mary Magdalen: Myth and Metaphor. New York: Riverhead Books.

17. Lacarra, E. (1993). ¿Magdalena de San Jerónimo: muger contra mugeres?. In Deyermond, A. \& Penny, R. (ed.), Actas del Primer Congreso Anglo-Hispano, Huelva, marzo 24-31, 1992. II. Literatura (pp. 175-189). Madrid. Recuperado el 12/11/2016 de https://www.academia.edu/5200901/_Magdalena_de_San_Jer\%C3\%B3nimo _muger_contra_mugeres

18. López Barahonā, V. (2013). La caza de vagabundas: trabajo y reclusión en Madrid durante la Edad Moderna. In I Congreso Internacional sobre la Historia de la Prisión y las Instituciones Punitivas, celebrado los días 10, 11 y 12 de abril de 2013 en la Universidad de Castilla La Mancha (Ciudad Real).

19. Malvern, M. (1975). Venus in Sackcloth, The Magdalen's Origins and Metamorphoses. Carbondale: Southern Illinois University Press.

20. Maravall, J.A. (2002) [1975]. La cultura del Barroco. Análisis de una estructura histórica. Barcelona: Ariel.

21. McKendrick, M. (1989). Theatre in Spain, 1490-1700. Cambridge: Cambridge University Press.

22. Melossi, D. \& Pavarini, M. (1982). Carcere e Fabbrica. Alle origini del sistema penitenziario (XVI-XIX secolo). Milano: il Mulino.

23. Mosco, M. (ed.) (1986). La Maddalena tra Sacro e Profano. Milano: Mondadori.

24. Pagden, A. (1995). Lords of All the World: Ideologies of Empire in Spain, Britain, and France, c.1500-1800. New Haven: Yale University Press.

25. Parker, G. (2010). Felipe II: La biografía definitiva. Barcelona: Planeta.

26. Shemek, D. (1998). Ladies Errant: Wayward Women and Social Order in Early Modern Italy. Durham: Duke University Press.

27. Simón Díaz, J. (ed.) (1982). Relaciones de actos públicos celebrados en Madrid (1541-1650). Madrid: Instituto de Estudios Madrileños.

28. Tamarit Sumalla, R. (2010). María Magdalena: "Ecce Mulier". Tarragona: Arola.

29. Tomás y Valiente, F., Clavero, B., Bermejo, J.L., Gacto, E. \& Álvarez Alonso, C. (eds.) (1990). Sexo barroco y otras transgresiones premodernas. Madrid: Alianza Editorial.

30. Torremocha Hernández, M. (2014). De la Mancebía a la Clausura. La Casa de Recogidas de Magdalena de San Jerónimo y el convento de San Felipe de la Penitencia (Valladolid, siglos XVI-XIX). Valladolid: Universidad de Valladolid. 
31. Vance, E. (1988). Semiotics and power: relics, icons, and the Voyage de Charlemagne à Jérusalem et à Constantinople. Romanic Review, 79(1): 164-183.

32. Vidal Gavídia, M.A (2001). La casa de arrepentidas de Valencia: origen y trayectoria de una institución para mujeres. Valencia: Consell Valencià de Cultura.

33. Williams, N. \& Fraser, A. (1972). The life and times of Elizabeth I. New York: Weidenfeld and Nicolson.

\section{Authors' Biodata}

Coral Cuadrada es profesora de archivística, historiografía, historia medieval e historia de la mujer en la Universidad Rovira i Virgili de Tarragona (URV), y también de historia de la mujer en el máster interuniversitario en estudios de la mujer, género y ciudadanía. En 1987 presentó en la Universidad de Barcelona una tesis de historia medieval sobre el Maresme, un estudio con el que ganó el Premio Iluro ese mismo año (El Mareme Medieval: Hàbitat, Economia $i$ Societat, XI-XIV siglos). Es investigadora del MARC (Centro de Investigación de Antropología Médica) de la URV, y del GRAMP (Grupo de Investigación de Arqueología Medieval y Postmedieval) de la UB. Coordina el máster interuniversitario en Estudios de la Mujer, Género y Ciudadanía. Es directora del Archivo de los Marqueses de Santa María de Barberà (Vilassar de Dalt, Barcelona). En relación con la historia de la mujer, ha coordinado y coeditado Dones, coneixement, societat (Reus, 2005), Igualdad y diferencia: pensamiento, acción, revisión (Madrid, 2008), Memòries de dones (Tarragona, 2009), Les dones als orígens de Torreforta (Tarragona, 2014) y Oikonomia: Cuidado, Reproducción, Producción (Tarragona, 2015).

Enric Olartecoechea es psicólogo social y máster en feminismos y masculinidades por la URV. Miembro del colectivo La Fondona, fondo de documentación feminista y LGTB Queer. Profesor de integración social del Instituto Miquel Tarradell, Barcelona. 